Universidad de Lima

Escuela de Posgrado

Maestría en Tributación y Política Fiscal

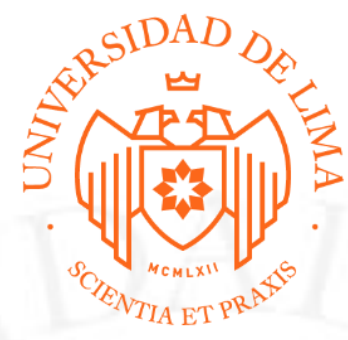

\title{
A PROPÓSITO DE LA DIGITALIZACIÓN DEL DINERO: LAS CRIPTOMONEDAS Y SU INCIDENCIA TRIBUTARIA EN EL PERÚ. EL CASO DEL BITCOIN
}

Trabajo de investigación para optar el Grado Académico de Maestro en Tributación y Política Fiscal

Diana Elizabeth Román Yrigoín

Código 20162752

Marco Antonio Meza Maúrtua

Código 20162734

\author{
Asesor \\ Juan Carlos Vidal Chang \\ Lima - Perú
}

Diciembre de 2019 


\section{A PROPÓSITO DE LA DIGITALIZACIÓN DEL DINERO: LAS CRIPTOMONEDAS Y SU INCIDENCIA TRIBUTARIA EN EL PERÚ - EL CASO DEL BITCOIN}




\section{ABOUT MONEY'S DIGITALIZATION: CRYPTOCURRENCIES AND THEIR FISCAL IMPACT IN PERU- THE BITCOIN CASE}




\section{TABLA DE CONTENIDO}

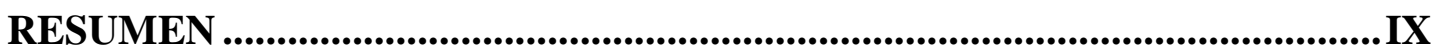

ABSTRACT ......................................................................................................

INTRODUCCIÓN

CAPÍTULO I: LAS CRIPTOMONEDAS, EL BITCOIN Y SU NATURALEZA JURÍDICO-ECONÓMICA .............................................................................. 3

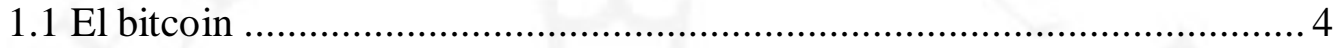

1.1.1 Origen y funcionamiento: ........................................................... 4

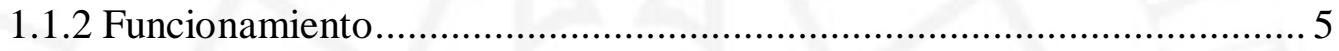

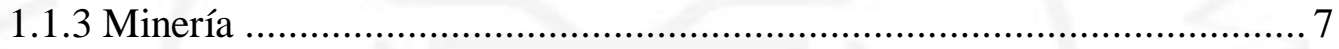

1.2 Naturaleza económica y jurídica.......................................................... 9

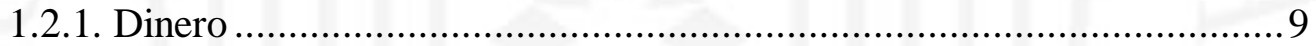

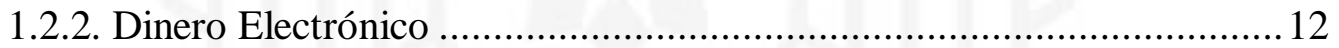

1.2.3. Moneda Virtual ................................................................................ 15

1.2.4. Valores Mobiliarios ............................................................................ 17

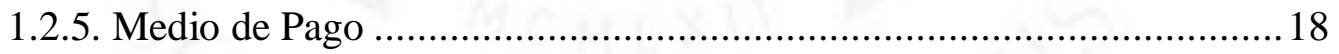

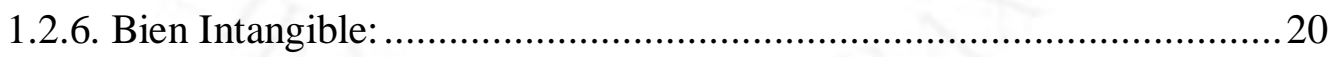

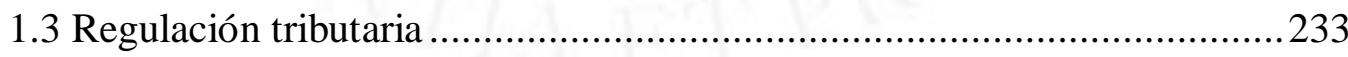

1.3.1 Disposiciones normativas en legislación comparada ..........................243

1.3.2. Disposiciones normativas en el Perú ..............................................2 28

CAPÍTULO II: EL IMPUESTO A LA RENTA Y LAS CRIPTOMONEDAS - EL CASO DEL BITCOIN ......................................................................................29

2.1 Las rentas que provengan del capital, del trabajo y de la aplicación conjunta de ambos factores 
2.2 Las ganancias de capital

CAPÍTULO III: LA IMPOSICIÓN AL CONSUMO Y LAS CRIPTOMONEDAS

- EL CASO DEL BITCOIN ..........................................................................43

3.1 La venta en el país de bienes muebles................................................. 45

3.2 La prestación o utilización de servicios en el país .................................51

3.3 La importación de bienes...............................................................57

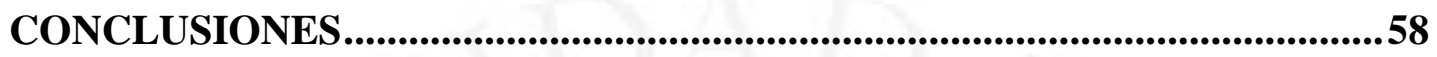

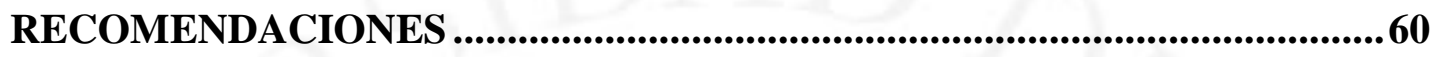

REFERENCIAS BIBLIOGRÁFICAS .....................................................6 


\section{ÍNDICE DE TABLAS}

Tabla 2.1: Aplicación del Impuesto a la Renta a la compra-venta de criptomonedas........34

Tabla 2.2: Aplicación del Impuesto a la Renta a la minería de bitcoins............................36

Tabla 2.3: Aplicación del Impuesto a la Renta a la utilización de las criptomonedas

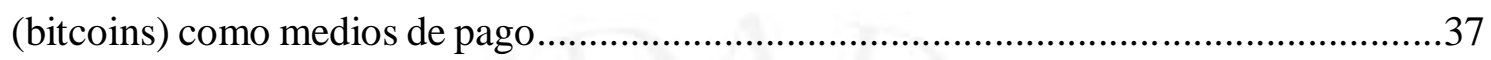

Tabla 2.4: Aplicación del Impuesto a la Renta a la compra-venta de criptomonedas realizada por personas naturales............................................................................ 41 


\section{ÍNDICE DE ANEXOS}

Anexo 1: Glosario y definiciones relacionadas al bitcoin......................................... 70

Anexo 2: Mapa mundial de establecimientos que aceptan bitcoins................................73

Anexo 3: Mapa del Perú de establecimientos que aceptan bitcoins..................................74

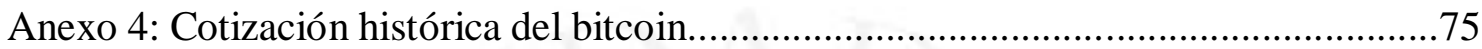




\section{RESUMEN}

En esta investigación se revisa la naturaleza jurídico-económica de las criptomonedas, con particular énfasis en el bitcoin, a fin de determinar la incidencia tributaria de la imposición a las ganancias y al consumo en las operaciones de compra-venta de bitcoins, en las que se emplean como medio de pago y el servicio de minado de bitcoins en el Perú. En ese contexto, se detallan los dispositivos legales que gravan dichas operaciones con el Impuesto a la Renta y el Impuesto General a las Ventas, así como la necesidad de una regulación especial tributaria en el Perú para las operaciones con criptomonedas.

Palabras clave: Criptomonedas, bitcoins, Impuesto a la Renta, Impuesto General a la Ventas, monedas virtuales. 


\begin{abstract}
In this investigation the legal and economic nature of cryptocurrencies is reviewed, with particular emphasis on bitcoin, in order to determine the tax impact of the corporate and personal income tax and the value added tax in the operations of buying and selling bitcoins, the ones in which they are used as a mean of payment and in the bitcoin mining service in Peru. In this context, we detail the legal devices that tax the operations with cryptocurrencies mentioned above with the Income Tax and the Value Added Tax, as well as the need for a special tax regulation in Peru for cryptocurrency operations.
\end{abstract}

Keywords: Cryptocurrencies, bitcoins, Income Tax, Value Added Tax, virtual currencies. 


\section{INTRODUCCIÓN}

En la actualidad van quedando muy pocos temas a la ciencia ficción que ya no se hayan materializado en la vida real. Así, dado el galopante avance tecnológico, muchas de las cosas con las que antes soñábamos producto de la lectura de un buen libro o después de una noche de cine, hoy son algo de uso frecuente.

Estos avances tecnológicos van alcanzando cada vez más, diversos aspectos de la vida cotidiana del ser humano, incluso se puede afirmar que desde algún tiempo atrás, la mayoría de las operaciones comerciales se pueden realizar empleando las tecnologías de la información y la comunicación (TIC), especialmente a través del Internet, que es la que más destaca, por lo que no caben dudas que su desarrollo revolucionó el mundo al punto de que actualmente es considerado como uno más de los servicios básicos que se contratan en los hogares.

En ese sentido, no resulta sorprendente que el uso de las referidas tecnologías alcance aspectos tan fundamentales como el económico y comercial, siendo estos aspectos en los que se han enfocado la gran mayoría de esfuerzos con la finalidad de simplificar y reducir los costos de las interacciones de los ciudadanos y también, evidentemente, generar réditos a quienes desarrollan dichos esfuerzos.

Entre estos esfuerzos se encuentran las criptomonedas, debiendo enfocarnos especialmente en el bitcoin, que tiene más de 10 años de existencia y es reconocida como la primera criptomoneda, cuyos usuarios en el Perú van aumentando, dado que ha despertado el interés de propios y extraños a nivel mundial en virtud del más que atractivo avance de su cotización, que inició en el 2010 en unos pocos centavos de dólar americano hasta llegar a los veinte mil dólares americanos durante el mes de enero de 2018 aunque retrocedió durante el 2019, cotizándose al cierre de este último año en siete mil cien dólares americanos. Estos sucesos no solo han despertado el interés de personas del sector privado sino también de los gobiernos dado que el bitcoin, al presentarse como una alternativa al uso del dinero convencional, conlleva a una serie de oportunidades y riesgos 
para las personas que decidan apostar por este producto, así como también la necesidad de los gobiernos de proteger a sus ciudadanos y también sus fuentes de financiamiento.

Ahora bien, como toda actividad económica que genera réditos, el uso del bitcoin se antoja de interés para las Administraciones Tributarias de los gobiernos, por las operaciones cada vez más frecuentes que se realizan con esta criptomoneda, las que se han traducido en la generación de riqueza y consumo. Además, resulta necesario señalar que por la particularidad de que no se requiere mayor información que la dirección de la cuenta donde están los bitcoins, sin mayor identificación de los usuarios de esta tecnología, también se presenta como una amenaza, dado que existen serios problemas con la trazabilidad de dichas operaciones, lo que conlleva una posibilidad latente de defraudación fiscal.

De acuerdo a lo antes señalado, nos surge la siguiente interrogante: ¿Las operaciones con criptomonedas se encuentra gravadas con el Impuesto a la Renta y/o el Impuesto General a las Ventas? Ahora bien, para responder la interrogante antes señalada, consideramos necesario primero responder las siguientes interrogantes: ¿Qué es una criptomoneda? ¿cómo se crean y cómo se emplean?, ¿Cuál es la naturaleza jurídicoeconómica de las criptomonedas? y si ¿Resulta necesario una normatividad especial en materia tributaria que regule el uso de las criptomonedas?

Con la finalidad de responder las interrogantes señaladas en el párrafo precedente, el presente trabajo de investigación se compone de tres capítulos. En el primero de ellos describiremos qué es el Bitcoin, cómo se crea y cuál es su naturaleza jurídico-económica. Posteriormente, en el segundo capítulo analizaremos la incidencia tributaria relacionada a la imposición a las ganancias y en el tercer capítulo trataremos la incidencia tributaria relacionada a la imposición al consumo, para concluir respondiendo si resulta necesario que se regule especialmente el uso de las criptomonedas y formulando algunas recomendaciones relacionadas con lo planteado en las interrogantes cuya respuesta investigaremos. 


\section{CAPÍTULO I: LAS CRIPTOMONEDAS, EL BITCOIN SU NATURALEZA JURÍDICO-ECONÓMICA}

A partir de la crisis económica originada por las hipotecas subprime o hipotecas basura y la desconfianza en las instituciones financieras producto de dicha crisis, es que se originan las denominadas criptomonedas o también denominadas monedas virtuales o criptoactivos (por el uso de la criptografía en su diseño). Nakamoto (2008) sostiene que la finalidad principal de estas es la de constituirse como una forma de dinero en efectivo electrónico, que será empleada exclusivamente punto a punto (peer-to-peer) y permitirá realizar pagos en línea directamente entre las partes sin pasar a través de una institución financiera (p. 1).

Jeff Kauflin (2018) reporta en Forbes que, a finales de febrero de 2018, existían más de 1,500 criptomonedas, cuyo valor en conjunto ascendía a U\$S 550 mil millones de dólares americanos, constituyendo este un indicador sumamente interesante que nos revela el nivel de aceptación a nivel mundial.

Por su parte, en una nota periodística publicada en el diario Gestión (2018), en marzo de 2018, Roger Benites Quijano ${ }^{1}$ afirmó que aproximadamente 12,600 peruanos adquirieron criptomonedas. Asimismo, en el citado diario se aseguró a inicios de junio de 2019 que el Perú es el tercer país con mayores transacciones de criptomonedas en Latinoamérica. La información citada nos revela la importancia que vienen adquiriendo las criptomonedas en el país.

Ahora bien, en esencia, todas las criptomonedas o criptoactivos están diseñadas empleando el uso combinado de la criptografía y las plataformas electrónicas, por lo que les corresponde el mismo tratamiento legal y tributario. En ese sentido, para fines prácticos y didácticos, en la presente investigación, el estudio se enfocará en la criptomoneda precursora que a su vez es la más representativa de ellas, es decir en el bitcoin como caso modelo, revisando en este capítulo su origen, cómo funciona, las

\footnotetext{
${ }^{1}$ La entrevista la brindó en calidad de CEO de la plataforma exchange de criptomonedas Bitinka.
} 
operaciones principales en las que se emplean, su naturaleza económica y jurídica, su valor en el mercado y su regulación tributaria, o falta de ella, en nuestro país como en la legislación de otros países.

\subsection{El bitcoin}

\subsubsection{Origen y funcionamiento:}

Son varios los autores que han escrito sobre el bitcoin, alguno de ellos se remiten a lo manifestado por el creador del sistema, señalando que el bitcoin es una moneda electrónica descentralizada (elbitcoin.org, 2012), mientras que otros solo la definen como una moneda digital (Gregersen E., 2016), asimismo, algunos señalan que el bitcoin es una criptomoneda privada que encuentra soporte en la verificación de las transacciones y el registro histórico de dichas transferencias (Chiu J. y Koeppl T., 2017).

Para Díaz Vico y Sánchez Aragó, el bitcoin es un bien digital en línea que se basa en la tecnología red entre iguales o P2P “peer-to-peer”, para la gestión de transacciones y distribución a diferencia del dinero fiduciario, cuyo valor se deriva a través de la regulación o ley y garantizado por el Estado, los bitcoins no tienen valor intrínseco y el único verdadero valor se basa en la oferta y la demanda, lo que la gente está dispuesta a negociar para ellos. El bitcoin es descentralizado, no está respaldado por ningún gobierno, ni depende de la confianza de un emisor central (Díaz Vico, Sánchez Aragó, 2014).

Ahora bien, el nombre de bitcoin también se emplea para referirse al software libre diseñado para la gestión de la moneda y también para la red P2P que le da soporte (elbitcoin.org, 2012).

La Organización para la Cooperación y el Desarrollo Económico (OCDE, 2018) las define como un activo digital usado como un medio de cambio y que se soporta en la criptografía para asegurar las transacciones, para controlar la creación de más de sus unidades y para verificar su transferencia. Es un tipo de moneda virtual, que se constituye como una unidad de cambio que no está respaldada por ningún gobierno o disposición legal. 
Satoshi Nakamoto, el programador que creó el sistema bitcoin (aunque se especula que este seudónimo es usado por un grupo de programadores) se inspiró en la necesidad de independizar el comercio por internet de las instituciones financieras, dado que a pesar de que el sistema funciona suficientemente bien, sufre de las debilidades inherentes al modelo basado en confianza, además de los costos que la mediación de las instituciones financieras importa a cada transacción (Nakamoto S., 2008). Por lo que, a diferencia de la mayoría de las monedas, el funcionamiento de bitcoin no depende de una institución central, sino de una base de datos distribuida, la que utiliza el sistema peer to peer (elbitcoin.org 2012).

Ahora bien, como mencionamos anteriormente, motivado por la desconfianza en los intermediarios "confiables" generada por la crisis financiera subprime, a finales del 2008, Nakamoto, mediante la publicación de "Bitcoin: A Peer-to-Peer Electronic Cash System", sentó las bases fundamentales del sistema bitcoin, proponiendo un sistema alternativo en la forma de realizar transacciones de dinero que emplean medios electrónicos, en el que para validar las operaciones se prescinde totalmente de intermediarios, recayendo la confiabilidad de las transacciones en las partes involucradas en la operación y en los demás usuarios del sistema bitcoin, a través de pruebas criptográficas por cada operación que quedan registradas de manera cronológica (proof of work) en una base de datos descentralizada que está formada por bloques de datos que se unen para formar una cadena (blockchain) que en otras palabras se traducen en un gran libro contable, al que tienen acceso todos los usuarios posibilitando la comprobación de todas las transacciones que se han hecho con un bitcoin.

Como dato a tener en cuenta, el sistema bitcoin y la generación de "monedas virtuales" no tiene un número ilimitado, ya que está diseñado para que solo se emita una cantidad de veintiún millones de unidades de bitcoins, generándose una similitud adicional con los bienes que se obtienen de la actividad económica de extracción minera, ya que estos también tienen un número finito.

\subsubsection{Funcionamiento}

Nakamoto define a la moneda virtual como una cadena de firmas; así, señala que la transacción de un bitcoin se realiza cuando su dueño la transfiere al próximo dueño, 
firmando digitalmente un hash de la transacción previa y la clave pública del próximo dueño, para añadir dichos datos al final de la moneda. El beneficiario de la transacción puede corroborar las firmas para verificar la cadena de propiedad (Nakamoto S., 2008).

Nakamoto señala que el funcionamiento de la red bitcoin se desarrolla en 6 pasos: 1) Cada nueva transacción es comunicada a todos los usuarios del sistema o también denominados nodos (nodes). 2) Cada uno de los nodos registra la transacción en bloque (block). 3) Cada uno de los nodos resuelve un problema matemático complejo que se constituye como una prueba de trabajo (proof of work). 4) Cada nodo al resolver la prueba de trabajo comunica a los demás nodos la resolución y el bloque generado. 5) Cada nodo aceptará el bloque si comprueba que todas las transacciones contenidas en él son válidas y los bitcoins empleados no han sido gastados con anterioridad. 6) Se deja constancia de la aceptación del bloque al momento de que los nodos inician una nueva prueba de trabajo sobre la anterior (Nakamoto S., 2008).

Con la finalidad de explicar de manera práctica lo señalado en los párrafos precedentes, describiremos una operación usual en la que se pueden emplear bitcoins como medio de pago: La compra de una pizza que $\mathrm{ABC}$ desea realizar desde su hogar a XYZ, utilizando medios electrónicos.

En nuestro ejemplo, la operación se podría realizar tradicionalmente empleando una tarjeta de crédito o débito como medio de pago o mediante una transferencia de dinero a la cuenta bancaria del vendedor, sin embargo, estas formas de pago involucran forzosamente la participación de un tercero en la operación, lo que demandará un tiempo de espera adicional para que el tercero valide que el medio de pago o cuenta bancaria empleada por $\mathrm{ABC}$ cuenta con los fondos necesarios para adquirir la pizza que vende XYZ. Esta validación también implica un costo adicional a la operación por la intervención del tercero quien obtendrá un porcentaje del importe involucrado en la operación.

Pues bien, en ese contexto, la propuesta de Nakamoto consiste en que, a fin de evitar la intervención del tercero, $\mathrm{ABC}$ realice el pago con un medio que $\mathrm{XYZ}$ pueda validar directamente, empleando llaves criptográficas que garanticen la operación. Tanto ABC como XYZ necesitarán una llave criptográfica de carácter pública y otra privada. La llave pública podríamos asemejarla a una dirección de correo electrónico que como 
sabemos es de conocimiento público, mientras que la llave privada podemos asemejarla a un certificado o firma digital. Entonces para efectuar la operación con bitcoins, ABC, usando su llave privada deberá firmar un resumen criptográfico (hash) de la transferencia previa, consignado además los datos de la llave pública del nuevo propietario, en nuestro caso los de la llave pública de XYZ, registrándose toda esta información al final de la moneda. El nuevo propietario a fin de corroborar que los bitcoins son de su propiedad, podrá verificar las firmas que históricamente se ingresaron en la moneda, las que se muestran como una cadena de bloques (blockchain), además de esperar la confirmación de los usuarios de la red (nodes) al aceptar la transacción.

Ahora bien, lo que garantiza que $\mathrm{ABC}$ no haya usado los bitcoins en más de una transacción es precisamente la cadena de bloques por la que está compuesta cada bitcoin, ya que los usuarios de la red solo aceptarán el bloque si es que se comprobó que las transacciones previas en dicho bloque son válidas y los bitcoins no fueron empleados en otra transacción por el mismo propietario. Además, dada la naturaleza pública de la red Bitcoin, todos los usuarios de esta pueden ingresar y verificar cada una de las transacciones que previamente se han realizado.

\subsubsection{Minería}

La minería es la actividad mediante la cual los usuarios (denominados mineros) ponen a disposición de la comunidad en red los distintos recursos de su ordenador, obtienen una cantidad de criptomonedas (Pérez, 2013).

Complementariamente a la noción desarrollada en el glosario ${ }^{2}$, cabe señalar que la minería es el proceso mediante el que los usuarios (denominados mineros) ponen a disposición de la comunidad en red los distintos recursos de su ordenador, obtienen una cantidad de criptomonedas (Pérez, 2013).

De acuerdo a Nakamoto, en el sistema Bitcoin, la primera transacción en un bloque es una transacción especial con la que comienza una moneda nueva, propiedad del

2 Ver Anexo 1. 
creador del bloque (Nakamoto S., 2008). Constituyendo esta nueva moneda la ganancia del minero.

A su vez con la creación del bloque se pone en circulación nuevas monedas, puesto que al no existir una autoridad central que las distribuya, ese papel lo desempeña el minero, al emitir la nueva moneda y eventualmente usarla en una nueva transacción.

Además, la adición estable de una constante de monedas nuevas es análoga a los mineros de oro que consumen recursos para añadir oro a la circulación. En el caso de los mineros, la inversión se encuentra en el tiempo empleado para las validaciones mediante la solución de las fórmulas matemáticas, los equipos informáticos empleados y la electricidad gastada (Nakamoto S., 2008).

Otra forma de incentivar el soporte de la red a través de la minería se basa en las comisiones por cada transacción que el minero confirme, dado que, si el valor de salida de una transacción es menor que el valor de entrada, la diferencia es una comisión por transacción que se añade al valor de incentivo del bloque que contiene la transacción (Nakamoto S., 2008).

\subsubsection{Operaciones frecuentes con bitcoins}

En la presente investigación, a fin de determinar la incidencia tributaria del uso de criptomonedas, nos enfocaremos en las operaciones frecuentes a nivel macro en las que se emplean bitcoins, es decir, no abordaremos detalles como los tipos de bienes que se adquieren o los servicios que se contratan en dichas operaciones, en ese sentido las operaciones que estudiaremos son:

1) Como un bien de cambio, es decir la compra-venta habitual de bitcoins, siendo esta operación a lo que se dedican las casas de cambio (exchange).

2) Como forma de pago en la adquisición de bienes y contratación de servicios; resultando de aplicación la operación descrita como ejemplo en el punto anterior: La compra de una pizza pagada mediante bitcoins.

3) La operación de minería de bitcoin, mediante la cual los usuarios de la red bitcoin (nodes) obtienen nuevas criptomonedas al resolver los problemas matemáticos que 
se convierten en la prueba de trabajo que confirman la validez de las operaciones con bitcoins y se registran en la cadena de bloques.

\subsection{Naturaleza económica y jurídica}

La naturaleza económica y jurídica del bitcoin ha sido bastante discutida. En el medio se han dictado muchas opiniones al respecto, por lo que en el presente punto expondremos las definiciones más relevantes, a efecto de determinar la naturaleza jurídico-económica del bitcoin, a partir de la cual desarrollaremos el tratamiento tributario del mismo en los siguientes capítulos.

\subsubsection{Dinero}

En el Glosario de términos económicos del Banco Central de Reserva del Perú ${ }^{3}$ (s.f.) encontramos que el Dinero es definido como:

"Activos financieros que cumplen las funciones de medio de pago, reserva de valor y unidad de cuenta. En sentido estricto, se refiere al circulante y los depósitos a la vista. Sin embargo, existen una clase amplia de otros activos que son sustitutos cercanos del dinero, llamado cuasidinero, que por innovación financiera pueden cumplir varias de las funciones del dinero".

Respecto a lo que debemos entender por Activo Financiero el Glosario citado lo define como "Activos de entidades sobre los que las unidades institucionales ejercen derechos de propiedad y de los que pueden obtenerse beneficios económicos: ganancias por tenencia o renta".

En cuanto al término cuasidinero lo define como:

"Activos financieros que son sustitutos cercanos del dinero, pero con menor grado de liquidez, tales como los depósitos a plazo, de ahorro, los certificados de depósito y bonos corporativos emitidos por las sociedades de depósito, entre otros. Son pasivos del sistema financiero que, pese a no ser directamente utilizables como medio de pago, pueden convertirse en dinero en poco tiempo".

3 En adelante BCRP. 
Por su parte Paul Krugman (2014) señala que la definición clásica del dinero es entenderlo como cualquier activo que puede usarse fácilmente para comercializar bienes y servicios. El dinero consiste en efectivo en sí mismo, el cual es líquido por definición, además de otros activos que son altamente líquidos (p. 412).

El autor indica que el dinero tiene tres roles, básicamente funciona como medio de pago, depósito de valor y unidad de cuenta.

- Cumple la función de medio de pago porque permite intercambiar por otros bienes y servicios.

- Se puede determinar el valor de cualquier bien y servicio en función de una cantidad de dinero.

- Es un medio de ahorro de las riquezas

Tenemos entre los tipos de dinero, el denominado dinero fiduciario, que es el más común y conocido, su valor deriva de su estatus oficial respaldado por el gobierno, en el caso peruano respaldado por el BCRP, quien es la autoridad encargada de la emisión y manejo de la política monetaria en el país.

Observamos que el bitcoin no encajaría dentro del término clásico de Dinero ni cuasidinero establecido por el BCRP, debido a que no se trata de un activo financiero circulante ni de un depósito a la vista, ni depósitos a plazo, de ahorro, o algún otro sustituto cercano del dinero.

No obstante, el bitcoin cumple en mayor o menor medida con las funciones del dinero, por ejemplo, es utilizado como medio de pago por una comunidad de usuarios que efectúa transacciones comerciales en la web ${ }^{4}$, incluso en el Perú encontramos empresas que ya lo aceptan como medio de pago ${ }^{5}$ (Candia S., 2018), con lo cual podríamos afirmar que el bitcoin cumple una de las funciones básicas del dinero.

4 A modo de anécdota, la primera transacción que se realizó fue cuando un usuario pagó a un intermediario 10,000 bitcoin para que le enviara una pizza (Antolini Guido, 2017).

5 Según Coinmap.com (web que muestra todos los comercios en el mundo que aceptan bitcoin) son más de 100 empresas en el Perú que afirman aceptar bitcoins como medio de pago, repartidas entre los departamentos de Piura, Cajamarca, Lima, Callao, Ica, Cusco, Arequipa, entre otros. 
Como unidad de cuenta consideramos que podría determinarse el valor de cualquier bien y servicio en función de una cantidad determinada de bitcoin, en el mismo sentido en el artículo de la web oroyfinanzas.com (2015) se señala que:

"su encaje conceptual estaría cercano al ámbito de los llamados en el mundo anglosajón LETS (Local Exchange Trading Systems). Se trataría de una categoría de bienes patrimoniales que son tomados como medida común de valor en sistemas de intercambio económico, cooperativos y descentralizados, ajenos al dinero fiduciario estatal, y basados en la confianza de los usuarios del sistema".

En cuanto a que funcione como reserva de valor, es poco probable que el bitcoin pueda ser un medio de ahorro de las riquezas debido a que es altamente volátil y el valor del mismo está en manos de la oferta y la demanda.

Por su parte, el BCRP señala en su web que las criptomonedas, entre ellas el bitcoin:

"son activos financieros no regulados, que no tienen la condición de moneda de curso legal ni son respaldas por bancos centrales. Asimismo, no cumplen plenamente las funciones del dinero como medio de cambio, unidad de cuenta y reserva de valor".

Como puede advertirse, el BCRP no descarta que el bitcoin cumpla con las funciones del dinero, pero no plenamente como el dinero fiduciario, además manifiesta su preocupación por los riesgos y factores especulativos que afectarían a los que lo adquieran.

En ese mismo sentido, el informe elaborado por Antoine B. y Vikram H. (2018), director adjunto en el departamento de estrategia, políticas y evaluación del Fondo Monetario Internacional, señala que el valor del bitcoin es tan volátil ${ }^{6}$ que tiene poca utilidad como unidad de cuenta o reserva de valor, además su aceptación aún es limitada por lo que su capacidad de medio de pago se encuentra restringida (p.27).

En el informe elaborado por KPMG, la economista Constance Hunter (2018), cuestiona que las criptomonedas cumplan con todos los criterios del dinero, así tenemos que, para cumplir con el requisito de reserva de valor las criptomonedas deben ser mucho

6 El Banco Mundial también coincide con la alta volatilidad del bitcoin (Banco Mundial, 2018). 
más estable, por ejemplo, si una persona efectúa un préstamo de bitcoin no tiene la seguridad de recibir el mismo valor inicialmente entregado. Asimismo, para que una moneda sea un medio de pago adecuado debe tener aceptación en una amplia jurisdicción, y esto se logra con la confianza, algo que aún no ha alcanzado las criptomonedas (p.34$37)$.

Por otro lado, en el citado informe se recoge la opinión de Coinbase, empresa líder que se dedica a realizar intercambios como brókers de criptomonedas ${ }^{7}$, quien considera que el bitcoin podría representar una reserva de valor en el futuro porque contiene un algoritmo que lo vuelve seguro y la demanda que fluctúa actualmente y que lo vuelve altamente volátil podría eventualmente estabilizarse a medida que el mercado madura.

De lo expuesto podemos afirmar que, al día de hoy los organismos financieros internacionales, Bancos Centrales, entre otros investigadores, cuestionan que las criptomonedas como el bitcoin sean dinero propiamente dicho, debido a que no encaja dentro de su definición y tampoco cumple plenamente con todas las funciones o roles del mismo. Además, no tienen respaldo de los bancos centrales como si lo tiene el dinero de curso legal de un país.

\subsubsection{Dinero Electrónico}

El dinero electrónico es un medio de pago que facilita las transacciones comerciales de bajo valor y gran volumen, la finalidad de este medio de pago es incluir a personas que no tienen acceso al sistema financiero (Vega Milton, 2013).

La ventaja del dinero electrónico es que cualquier persona hasta de las zonas más alejadas puede realizar de manera sencilla, segura, accesible y confiable transferencias de dinero, solo necesita un teléfono móvil básico para enviar un SMS y transmitir dinero virtual a otros teléfonos, en caso de requerir recargar dinero en la cuenta virtual se tiene que visitar a un agente y cambiar moneda física por dinero electrónico que automáticamente se deposita a su cuenta (BBVA Research, 2015).

7 Se dedican a realizar intercambios como brókeres de Bitcoin, Bitcoin Cash, Ethereum, Ethereum Classic y Litecoin con monedas fiduciarias en alrededor de 32 países, y transacciones de bitcoins y almacenamiento en 190 países en todo el mundo. 
Un ejemplo exitoso de la utilización del dinero electrónico se da en África donde se ha extendido su uso hasta representar el $80 \%$ de las cuentas de dinero electrónico existentes, esto debido a las condiciones socioeconómicas de dicha región en la que gran mayoría de la población está excluida del sistema financiero (BBVA Research, 2015).

Este dinero es almacenado en dispositivos electrónicos como teléfonos móviles la cual está asociada a una cuenta de dinero electrónico, similar a un monedero electrónico que puede utilizarse para el pago de servicios o adquisición de bienes.

La creación del dinero electrónico se realiza de la siguiente manera: el emisor entrega el dinero electrónico a sus agentes a cambio de efectivo o un depósito bancario de igual valor, los agentes a su vez entregan el dinero electrónico al usuario a cambio de efectivo, este a su vez puede utilizarlo en las transacciones comerciales con los establecimientos afiliados que reciben el dinero electrónico y que entregan al emisor inicial a cambio de dinero en efectivo.

\section{$\underline{\text { Regulación del dinero electrónico en el Perú }}$}

En el Perú el dinero electrónico fue regulado por la Ley $\mathrm{N}^{\circ} 29985$ - Ley de Dinero Electrónico, publicado el 17 de enero de 2013, y su reglamento aprobado mediante Decreto Supremo No 090-2013-EF, el 14 de mayo de 2013.

Debemos mencionar que el reglamento de la Ley $\mathrm{N}^{\circ} 29985$ fue modificado por el literal d) del artículo 1 de la Ley $\mathrm{N}^{\circ}$ 30404, publicada el 30 de diciembre de 2015, debido a que se buscó incluir a las personas jurídicas que no tuvieran acceso al sistema financiero.

En dicha norma se establece las características básicas del dinero electrónico como instrumento de inclusión financiera, en tal sentido, la norma regula la emisión de dinero electrónico, determina las empresas autorizadas a emitirlo y establece el marco regulatorio y de supervisión de las Empresas Emisoras de Dinero Electrónico, conforme a lo establecido en el artículo 1 de la norma citada.

De acuerdo al artículo 2 de la Ley $\mathrm{N}^{\circ}$ 29985, el dinero electrónico tiene las siguientes características:

- Es almacenado en soporte electrónico. 
- Es aceptado como medio de pago por entidades o personas distintas del emisor y tiene efecto cancelatorio.

- Es emitido por un valor igual a los fondos recibidos.

- Es convertible a dinero en efectivo según el valor monetario del que disponga el titular, al valor nominal.

- No constituye depósito y no genera intereses.

Cabe indicar que solo pueden emitir dinero electrónico las empresas que operan bajo el ámbito de supervisión de la Superintendencia de Banca, Seguros y Administradoras Privadas de Fondos de Pensiones (en adelante SBS), en ese sentido, dicha entidad establece las modalidades de contratación aplicables al dinero electrónico, las que pueden ser escritas, electrónicas u otras, conforme a lo establecido en los artículos 3 y 6 de la Ley $N^{\circ} 29985$.

Con posterioridad a la publicación de la norma, en febrero del 2016 la Asociación de Bancos del Perú puso en marcha la billetera móvil denominada "BIM", mediante la cual puede almacenarse dinero electrónico a fin de efectuarse operaciones comerciales desde el teléfono celular sin tener la necesidad de usar el dinero en efectivo, inclusive no se tiene la necesidad de contar con internet porque basta con enviar un mensaje de texto, por ello el dinero electrónico en esta plataforma no necesita que los usuarios tengan una cuenta bancaria (Montoya Karina: 2016).

Coincidimos con la opinión de Manuel Cipriano Pirgo que considera que el dinero electrónico no es una nueva moneda o un título valor que nace a partir de la ley, sino que constituye la virtualización de los servicios financieros ya existentes (Cipriano Pirgo: 2015)

Cabe señalar que la actividad de emisión de dinero electrónico efectuadas por las empresas emisoras de dinero electrónico se encuentra gravada con el Impuesto General a las Ventas, sin embargo, se estableció la exoneración por tres (3) años, contados a partir de la vigencia de la Ley $\mathrm{N}^{\circ} 29985$, siendo prorrogada dicha exoneración mediante Ley N³0899 hasta el 31 de diciembre del 2019. 
Tampoco estará sujeta al pago del Impuesto a las Transacciones Financieras - ITF toda vez que se busca promover el uso de dicho medio de pago por las personas que por sus escasos recursos no tienen acceso a la banca.

En este punto debemos mencionar que el Bitcoin no cumple con las características del dinero electrónico a pesar de que puede ser transado, no se emite a cambio de fondos por lo que su valor no está respaldado como en el caso del dinero electrónico que tiene respaldo su representación monetaria.

De otra parte, el Bitcoin no está regulado como sí lo está el dinero electrónico mediante la Ley $\mathrm{N}^{\circ} 29985$ y su reglamento. Asimismo, tampoco se encuentra supervisado por alguna entidad estatal como si sucede con el dinero electrónico que se encuentra bajo la supervisión de la SBS.

En el caso Español tampoco califica como moneda electrónica desde un punto de vista jurídico, porque el bitcoin no forma parte de ningún sistema monetario y así lo afirma Fernández Burgueño pues en la Ley 21/2011 de 26 de junio de 2011 se define dinero electrónico como todo valor monetario almacenado por medios electrónicos o magnéticos que represente un crédito sobre el emisor, que se emita al recibo de fondos con el propósito de efectuar operaciones de pago y que sea aceptado por una persona física o jurídica distinta del emisor de dinero electrónico, con lo cual según el autor citado falta en el bitcoin ese respaldo de un crédito contra el emisor, por la sencilla razón de que ese emisor no existe (Fernández P., 2013).

\subsubsection{Moneda Virtual}

El Banco Central Europeo publicó en su informe "Virtual Currency Schemes" (European Central Bank, 2012) la definición de monedas virtuales, señalando que son un tipo no regulado de moneda digital, que es emitida y usualmente controlada por sus desarrolladores, y es utilizada y aceptada por miembros de una comunidad virtual específica $^{8}$. Por otra parte, en su página web (Banco Central Europeo, 2018) publicó que el bitcoin:

8 Frase Original: "a virtual currency is a type of unregulated, digital money, which is issued and usually controlled by its developers, and used and accepted amog the members of a specific virtual community". 
"En esencia, es una unidad de valor digital que puede ser intercambiada electrónicamente. No tiene existencia física. Su creación y seguimiento se hacen mediante una red de ordenadores utilizando complejas fórmulas matemáticas, y no a través de una única autoridad u organización.”

Por lo tanto, en buena cuenta las monedas virtuales no son más que una representación digital de valor y que no representan un crédito sobre el emisor como si lo tienen el dinero fiduciario.

Por su parte, el BCRP en una publicación a cargo de Meza, Anthony y Vega, Milton (2017) se refieren al bitcoin como la primera moneda virtual, y señala que son un activo digital que puede ser utilizado como medio de pago por un grupo de personas que acuerdan su aceptación, por lo que recomienda que las autoridades evalúen si se los reconoce como activos de inversión o como medio de pago, se determinen qué instituciones pueden vender y comprar dicha moneda, cómo proteger al cliente, la aplicación de las normas sobre lavado de activos y el financiamiento del terrorismo, además de definir el tratamiento tributario.

Pues bien, la Gerencia de Estudios Económicos de la Asociación de Bancos del Perú - ASBANC (Asbanc Semanal N²74, 2018), recoge como definición de monedas virtuales la citada por Bitlicense, la primera licencia para el funcionamiento de monedas virtuales emitido por el Estado de Nueva York, indicando que moneda virtual es "cualquier tipo de unidad digital, creada u obtenida mediante el cálculo matemático, cuyo sistema está basado en internet y que se utiliza como un medio de cambio o una forma de valor digitalmente almacenado".

De lo expuesto, se aprecia que existe cierto consenso en el sector financiero de catalogar a las criptomonedas como monedas virtuales, entendiendo que tienen existencia dentro del mundo virtual y que pueden utilizarse como medio de intercambio debido a que son aceptadas de forma consensuada por una comunidad.

Cabe precisar que las monedas virtuales están dentro del concepto de dinero digital, siendo que este último se define como cualquier medio de intercambio monetario que se realiza por medios electrónicos, en tal sentido, también se encontrarían dentro de este concepto el pago con tarjetas de crédito o débito, es decir, todo aquello que se realiza mediante medios electrónicos. 
El surgimiento de las monedas virtuales es el resultado del gran avance tecnológico y la tendencia es que el dinero fiduciario desaparezca, según la ex Directora Gerente del Fondo Monetario Internacional, por lo que recomienda a los Bancos Centrales adoptar medidas para promover la creación de monedas virtuales de forma que mantengan la emisión y el control de las mismas, otorgándoles respaldo legal (Christine Lagarde, 2018).

\subsubsection{Valores Mobiliarios}

Al respecto, el artículo 3 de la Ley de Mercado de Valores ${ }^{9}$ establece que "Son valores mobiliarios aquellos emitidos en forma masiva y libremente negociables que confieren a sus titulares derechos crediticios, dominiales o patrimoniales, o los de participación en el capital, el patrimonio o las utilidades del emisor." Por su parte, el artículo 255.1 de la Ley de Títulos Valores ${ }^{10}$ dispone que:

"Son valores mobiliarios aquellos emitidos en forma masiva, con características homogéneas o no en cuanto a los derechos y obligaciones que representan. Las emisiones podrán estar agrupadas en clases y series. Los valores pertenecientes a una misma emisión o clase que no sean fungibles entre sí, deben estar agrupados en series. Los valores pertenecientes a una misma serie deben ser fungibles. Los valores sobre los cuales se hayan constituido derechos reales u otra clase de cargos o gravámenes dejan de ser fungibles, no pudiendo ser transados en los mecanismos centralizados de negociación, salvo que se trate de su venta forzosa."

Como se aprecia, las criptomonedas no califican como valores mobiliarios, al no cumplir con las características que la normativa especializada señala para ser consideradas como tal, debido a que no provienen de la emisión masiva de una entidad centralizada ni otorgan a su titular derechos y obligaciones ni participación alguna en el capital o patrimonio del emisor.

En efecto, los bitcoins se originan cuando el sistema informático recompensa al minero con la entrega de nuevos bitcoins por su actividad de validación de las operaciones

9 Cuyo Texto Único Ordenado ha sido aprobado por el Decreto Supremo N. ${ }^{\circ}$ 093-2002-EF y normas modificatorias.

10 Aprobado mediante Ley $\mathrm{N}^{\circ} 27287$, publicada el 19 de junio de 2000 y normas modificatorias. 
o transacciones efectuadas con criptomonedas; en tal sentido, no son emitidos por una entidad centralizada como sí lo son los valores mobiliarios.

\subsubsection{Medio de Pago}

El bitcoin nació como producto de un invento tecnológico y su principal objetivo fue funcionar como medio de pago en transacciones de compra-venta de bienes y/o servicios realizados mediante la web electrónica, es decir facilita a los usuarios a realizar transacciones virtuales con un solo medio de pago, aceptado por todos y sin la necesidad de un tercero que otorgue la validación a la operación, ahorrando tiempo y dinero ${ }^{11}$.

No obstante, la calidad de medio de pago ha tenido muchas críticas, siendo el principal argumento que al carecer del respaldo de un banco central se vuelven altamente volátil, lo cual a su vez le resta legitimidad como medio de pago e impide su aceptación generalizada a nivel mundial, característica que por ejemplo si presenta el dólar.

Ahora bien, en el Perú mediante la Ley N 29440 - Ley de los Sistemas de Pagos y de Liquidación de Valores - se establece el régimen jurídico de los Sistemas de Pagos y de Liquidación de Valores. Conforme explica el BCRP (2019) en su página web:

"Los Sistemas de Pagos y de Liquidación de Valores permiten la cancelación de las obligaciones y la transferencia de valores entre los agentes económicos y constituyen el canal de ejecución de las operaciones de política monetaria, encontrándose directamente vinculados con los sistemas bancarios y financieros. En ese contexto, el BCRP y la Superintendencia del Mercado de Valores autoriza, regula y supervisa los Sistemas de Pagos y de Liquidación de Valores, respectivamente, en beneficio del interés general."

Cabe destacar que las criptomonedas no han sido reconocidas como un medio de pago autorizado o regulado por el BCRP, por lo tanto, no califican como medio de pago de conformidad con lo establecido en la Ley $\mathrm{N}^{\circ} 29440$.

11 Las operaciones con el tercero validador pueden tardar días e incluyen un costo por el servicio de validación mientras que las operaciones con Bitcoin se validan en aproximadamente diez minutos y por lo general sin costo, salvo excepciones que en virtud de las cantidades de bitcoins que se empleen en la operación, tendrán un porcentaje como comisión para los usuarios que validen o confirmen dicha operación. 
Por otra parte, mediante la Ley $\mathrm{N}^{\circ} 28194$ - Ley para la Lucha contra la Evasión y para la Formalización de la Economía - se establece los supuestos en los cuales obligatoriamente se utilizarán los medios de pago con la finalidad de evitar la evasión y promover la formalización de la economía en el Perú, con lo cual, se entiende por medios de pagos los utilizados a través de empresas del Sistema Financiero, tales como: depósitos en cuenta, giros, transferencias de fondos, órdenes de pago, tarjetas de débito y crédito expedidas en el país, cheques, remesas y cartas de crédito $^{12}$.

De otra parte, la norma señala que mediante decreto supremo refrendado por el Ministro de Economía y Finanzas se podrá autorizar el uso de otros Medios de Pago considerando, entre otros, su frecuencia y uso en las empresas del Sistema Financiero o fuera de ellas.

No obstante, la citada norma no incorpora una definición legal de lo que debe entenderse como medio de pago cuyo uso se encuentra fuera del Sistema Financiero. El glosario de términos del Banco Central de Reserva del Perú (s.f.), señala que son medios de pago distintos al efectivo aquellos instrumentos de pago que permiten a los usuarios transferir fondos sin utilizar efectivo como los cheques, transferencias de crédito, débitos directos, tarjetas de débito y tarjetas de crédito.

La Asociación de Supervisores Bancarios de las Américas (ASBA) considera como medio de pago al bien o instrumento que puede ser utilizado para adquirir bienes, servicios y/o cancelar todo tipo de obligaciones, siendo el dinero el bien que cumple por excelencia con dicha función. Además de este, existen otros productos bancarios que han ido ganando aceptación como medio de pago, tales como las tarjetas de débito, tarjetas de crédito y los cheques, entre otros (ASBA, 2017).

En atención a lo mencionado, observamos que los denominados productos virtuales, tales como el bitcoin, en el Perú no se encuentran considerados como medio de pago, dado que a pesar de que se puedan adquirir bienes o contratar servicios de ciertas personas que lo aceptan, no se pueden emplear para pagar todo tipo de obligaciones, siendo que además la Ley $\mathrm{N}^{\circ} 28194$ ni alguna otra norma publicada con posterioridad los

12 El listado de medios de pago considerados por la Ley $\mathrm{N}^{\circ} 28194$ fue modificado mediante Ley $\mathrm{N}^{\circ} 30730$ que incorpora a las remesas y a las cartas de crédito, eliminando además la cláusula obligatoria de no negociable a los cheques. 
aceptan como tal, en consecuencia, dentro del ordenamiento jurídico peruano no es reconocido como medio de pago.

\subsubsection{Bien Intangible:}

Dado que las monedas virtuales no constituyen dinero ni medio de pago reconocido legalmente en el Perú, corresponde determinar si las criptomonedas constituyen bienes muebles y qué clase de bienes muebles.

De acuerdo con el Código Civil Peruano en su artículo 886 establece que son bienes muebles:

1) Los vehículos terrestres de cualquier clase.

2) Las fuerzas naturales susceptibles de apropiación.

3) Las construcciones en terreno ajeno, hechas para un fin temporal.

4) Los materiales de construcción o procedentes de una demolición si no están unidos al suelo.

5) Los títulos valores de cualquier clase o los instrumentos donde conste la adquisición de créditos o de derechos personales.

6) Los derechos patrimoniales de autor, de inventor, de patentes, nombres, marcas y otros similares.

7) Las rentas o pensiones de cualquier clase.

8) Las acciones o participaciones que cada socio tenga en sociedades o asociaciones, aunque a éstas pertenezcan bienes inmuebles.

9) Los demás bienes que puedan llevarse de un lugar a otro.

10) Los demás bienes no comprendidos en su artículo $885^{\circ}$ (el cual señala que son considerados como inmuebles).

Como puede apreciarse, las criptomonedas no se encuentran dentro de los supuestos a que se refieren los incisos 1 al 9 del artículo 886 del Código Civil; no obstante, el inciso 10 del mencionado artículo ha establecido que son bienes muebles los demás bienes no comprendidos en el artículo 885 , siendo que este último artículo regula los 
supuestos de bienes inmuebles ${ }^{13}$, con lo cual dado que los bitcoin no son bienes inmuebles, entonces calificarían como bienes muebles.

Ahora bien, el diccionario de la Real Academia Española ha señalado que la palabra intangible significa "que no debe o no puede tocarse" (Real Academia Española, S.f.), encajando perfectamente dentro de esa definición las criptomonedas las cuales se encuentran dentro del mundo virtual.

Respecto a la regulación de los bienes incorporales el Código Civil en su artículo 884 dispone que se rijan por su legislación especial.

En el Perú tenemos como regulación especial sobre bienes incorporales solo la Ley de Derecho de Autor y la Ley de Propiedad Industrial, respecto a la primera, está regulada por el Decreto Legislativo $N^{\circ} 822$ la cual tiene por objeto la protección de los autores de las obras literarias y artísticas y de sus derechohabientes, de los titulares de derechos conexos al derecho de autor reconocidos en ella y de la salvaguardia del acervo cultural. En cuanto a la segunda, está regulada por el Decreto Legislativo $\mathrm{N}^{\circ} 823$ en el cual se establece que se reconoce la protección de patentes de invención, certificados de protección, modelos de utilidad, diseños industriales, secretos industriales, marcas colectivas, marcas de certificación, nombres comerciales y denominaciones de origen.

Adicionalmente en el Perú rigen las normas de la Comunidad Andina tales como la Decisión 351 "Régimen Común sobre Derecho de Autor” y 486 "Régimen Común sobre Propiedad Industrial”.

De lo expuesto, se aprecia que no tenemos una definición general de intangible debido a que a la fecha no existe una regulación específica sobre la materia.

Respecto al Bitcoin, de acuerdo a la definición de la Real Academia española encajaría en la definición de intangible porque se trata de un producto virtual creado mediante la realización de cálculos matemáticos. De otra parte, las normas sobre derecho

13 El artículo 885 del Código Civil establece que son bienes inmuebles el suelo, el subsuelo, sobresuelo, el mar, los lagos, los ríos, los manantiales, las corrientes de agua, las minas, canteras, depósitos de hidrocarburos, los diques y muelles, las concesiones para explotar servicios públicos, las concesiones mineras obtenidas por particulares, los derechos sobre inmuebles inscribibles en el registro, los demás bienes a los que la ley les confiere tal calidad. 
de autor y propiedad industrial no son aplicables al Bitcoin porque no está comprendido dentro su ámbito de aplicación.

En este punto, resulta pertinente recapitular que, de las diversas definiciones revisadas, descartamos que el bitcoin sea dinero, en alguna de sus formas, fiduciario o electrónico. Asimismo, no califica como medio de pago ni valores mobiliarios según lo regulado en nuestro ordenamiento jurídico, advirtiéndose que las criptomonedas no son aceptadas como instrumento para cancelar todo tipo de obligación, ya que, por ejemplo, actualmente no se pueden cancelar obligaciones con el Estado como las de índole tributaria.

Por su parte, el abogado español Pablo Fernández Burgueño definió el bitcoin como bienes muebles, digitales, no fungibles y de propiedad privada, en forma de unidad de cuenta y creado mediante un sistema informático, utilizado como medida común de valor por acuerdo de los usuarios del sistema (Fernández P., 2013).

En consecuencia, el bitcoin califica como un bien mueble intangible, al no ser corpóreo, y presentar carácter informático y digital, por ser desarrollado a través de un software y encontrarse en la nube. Este bien puede formar parte del activo de una empresa o puede ser empleado como un bien de cambio, dependiendo de la actividad a la que se dedica la empresa y la finalidad con la que se adquieren los bitcoins.

Ahora bien, la Ley del Impuesto a la Renta tampoco ha definido qué es un activo intangible ni las características que lo identifican como tal, por lo que acudimos a las Normas Internacionales de Contabilidad, específicamente a la NIC 38 - Activos Intangibles, la cual en su punto 8 establece que se debe entender por activo al recurso controlado por el sujeto como resultado de sucesos pasados y del cual se espera obtener beneficios económicos en el futuro. Agrega que un activo intangible es aquel identificable de carácter no monetario y sin apariencia física ${ }^{14}$.

14 El tercer párrafo del punto 8 de la NIC 38 señala que son activos monetarios tanto el dinero en efectivo como otros activos por los que se van a recibir unas cantidades fijas o determinables de dinero. Al respecto, cabe señalar que en la operación en la que se emplean los bitcoins como forma de pago, estos no serán intercambiados únicamente por dinero sino por otros bienes o servicios, por lo que afirmamos que no califican como activos monetarios de acuerdo a la definición antes descrita. 
Respecto a la calificación como activo intangible ${ }^{15}$, la NIC señala que este debe ser identificable, condición que se cumple si el bitcoin es susceptible de ser separado o escindido del sujeto y vendido, transferido o intercambiado, individualmente o junto con un contrato, entre otras, o si surge de derechos contractuales o de otros derechos de tipo legal.

Asimismo, el sujeto deberá ejercer el control sobre el bitcoin, teniendo el poder de obtener los beneficios económicos futuros y pueda restringir el acceso a terceras personas a tales beneficios.

Al respecto, la NIC establece que la capacidad de control de los beneficios económicos futuros debe encontrar su justificación, en derechos legales exigibles ante los tribunales. Agrega que, no obstante, la exigibilidad legal del derecho sobre el elemento no es una condición necesaria para la existencia de control, puesto que el control puede ser ejercido de alguna otra manera, eso sí, esta manera debe ser demostrable. En este caso los bitcoins cumplen con esta característica, toda vez que su propiedad otorga el control legal de los beneficios económicos futuros que puede originar su uso.

De otra parte, la NIC también establece criterios para que el elemento sea reconocido como un activo intangible, siendo tales que sea probable que los beneficios económicos futuros atribuidos al elemento fluyan hacia el sujeto y que el costo del activo pueda ser medido de forma fiable. Al respecto, cabe señalar que los bitcoins cumplen con ambos criterios, dado que es muy probable que con su enajenación se generen beneficios económicos y además su costo es medido en función al precio de adquisición.

En consecuencia, los bitcoins califican como activos intangibles según las Normas Internacionales de Contabilidad.

\subsection{Regulación tributaria}

A continuación, analizaremos la regulación tributaria del bitcoin en la legislación comparada y en el Perú.

15 En el punto 12 de la NIC estudiada se detalla las características que debe reunir un elemento para calificar como activo intangible y aplicarle las disposiciones contenidas en dicha norma. 


\subsubsection{Disposiciones normativas en legislación comparada}

En Estados Unidos, la agencia tributaria denominada Internal Revenue Service (IRS) emitió en el año 2014 el comunicado 2014-21, señalando que para propósitos fiscales las monedas virtuales tienen el tratamiento de bienes o "property", en su idioma original, rechazando que se le otorgue el tratamiento tributario de una moneda extranjera. En consecuencia, la venta o cambio de moneda virtual o su uso como medio de pago puede ser objeto de obligaciones impositivas para con el fisco. Adicionalmente, se impuso la obligación de informar todas las transacciones realizadas con bitcoin u otras monedas virtuales en dólares (Small: 2015, p. 615).

Del mismo modo en Canadá, la agencia tributaria denominada Canadian Revenue Agency (CRA) señala que las criptomonedas tienen las características de un "commodity" y no son monedas de curso legal, por lo tanto, el uso de ellos para pagar bienes o servicios debe tratarse como un intercambio de bienes ${ }^{16}$ (Library of Congress, s.f.).

En el caso de Alemania, el ministerio de finanzas reconoce al bitcoin como unidad de cuenta, aceptando su uso como medio de pago en transacciones privadas pequeñas, mas no de aquellas transacciones comerciales (Small:2015 p. 619).

En España, el Ministerio de Hacienda de España publicó el Plan de Control Tributario de 2018 mediante el Boletín Oficial del Estado $N^{\circ} 20^{17}$ (Agencia Estatal Boletín Oficial del Estado, 2018), en el que se aprobaron las directrices generales de la Agencia Tributaria para el Control Tributario y Aduanero del 2018, indicándose, entre la importancia de la revisión de temas tales como:

"La utilización por el crimen organizado de la internet profunda o "deep web", para el tráfico y comercio de todo tipo de bienes ilícitos, así como el empleo de criptomonedas tipo "bitcoin" o similar como medios de pago, es uno de los desafíos más exigentes en la actualidad. Para afrontar esta amenaza, se potenciará el uso por las unidades de investigación de la Agencia

\footnotetext{
16 Frase original: "The Canada Revenue Agency (CRA) "has characterized cryptocurrency as a commodity and not a government-issued currency. Accordingly, the use of cryptocurrency to pay for goods or services is treated as a barter transaction".

17 Publicado el 23 de enero de 2018.
} 
Tributaria de las nuevas tecnologías de recopilación y análisis de información en todo tipo de redes".

Por otro lado, señala que continuarán las líneas de investigación iniciadas en años anteriores, destacando el estudio de la incidencia fiscal de nuevas tecnologías, como blockchain y en especial las criptomonedas.

Como puede apreciarse la agencia en sus declaraciones parece considerar al bitcoin como un medio de pago, lo cual estaría acorde con el pronunciamiento del Tribunal de Justicia de la Unión Europea (Sala Quinta) con fecha 22 de octubre de 2015 en la sentencia en el caso Hedqvist ${ }^{18}$ en el que señaló que el Bitcoin es una divisa virtual de flujo bidireccional y no tiene ninguna finalidad distinta de la de ser un medio de pago, considerándola exclusivamente como tal.

Cabe mencionar que a la fecha del presente trabajo, la Secretaría de Estado de Hacienda Dirección General de Tributos de España ha publicado quince (15) consultas tributarias vinculantes, relacionadas a los Bitcoin.

Sobre el particular, queremos destacar las Consultas $\mathrm{N}^{\circ}$ V1028-15 y V1029-15 de fecha 30 de marzo de 2015, se le consultó por la compra-venta de monedas como el bitcoin a través de máquinas de vending o cajeros y su sujeción al Impuesto sobre el Valor Añadido de dicha actividad. Ante ello la agencia tributaria señaló que "Las monedas virtuales Bitcoin actúan como un medio de pago y por sus propias características deben entenderse incluidas dentro del concepto "otros efectos comerciales" por lo que su trasmisión debe quedar sujeta y exenta del Impuesto". Explica que, conforme a lo señalado por la Abogada General en el asunto C-461/12, Granton Advertising, la frase “otros efectos comerciales" está referida a aquellos derechos que, sin ser un crédito o un cheque, confieren un derecho a una determinada cantidad de dinero, es decir, derechos que en el tráfico son considerados similares al dinero, como la propia entrega de dinero.

Como puede observarse la Agencia Tributaria considera que la compra-venta de bitcoin están exentas del Impuesto al Valor Añadido - IVA, debido a que son medios de

18 La controversia versó entre el Skatteverket (administración tributaria sueca) y el Sr. Hedqvist, en relación con un dictamen previo emitido por la Skatterättsnämnden (Comisión de Derecho Fiscal) sobre la sujeción al impuesto del valor añadido de las operaciones de cambio de divisas tradicionales por la divisa virtual «bitcoin», o viceversa, que el Sr. Hedqvist deseaba realizar por medio de una sociedad (en adelante caso Hedqvist). 
pago y se encuentran dentro de las operaciones exentas del Impuesto al igual que la compra-venta de dinero fiduciario.

Por otro lado, en la Consulta $\mathrm{N}^{\circ}$ V0999-18 de fecha 18 de abril de 2018, la agencia tributaria respondió a la consulta de una persona física que adquirió como inversión monedas virtuales tales como bitcoin y luego los intercambió por otras monedas virtuales como Ethereum, Ripple y Bitcoin Cash, habiendo empleado plataformas de intercambio con sede en territorio extranjero.

Al respecto, la agencia señaló que las monedas virtuales son bienes inmateriales y diferentes por lo tanto el intercambio de ellas constituye una permuta, las cuales generan la obtención de renta que se califica como ganancia o pérdida patrimonial para el contribuyente. Además, en cuanto a la cuantificación de dichas rentas, establece que se les aplique las reglas contenidas en la Ley 35/2006 del 28 de noviembre de 2006, referida al Impuesto sobre la Renta de las Personas Físicas, la cual señala que el importe de las ganancias o pérdidas patrimoniales será la diferencia entre los valores de adquisición y transmisión de los elementos patrimoniales, valores que serán tomados siempre que no resulten inferiores al valor de mercado, en cuyo caso prevalecerá el valor de mercado.

Ahora bien, en cuanto a qué debemos entender por valor de mercado correspondiente a las monedas virtuales que se permutan, la agencia señala que se refiere "al precio acordado para su venta entre sujetos independientes en el momento de la permuta". Por otro lado, establece que el importe que resulte de las ganancias o pérdidas patrimoniales provenientes de las operaciones de permuta entre monedas virtuales, así como las diferencias patrimoniales derivadas del intercambio de monedas virtuales por dinero, constituyen rentas del ahorro, por lo tanto, se integran y compensan en la base imponible del ahorro. Por último, estableció que las operaciones de intercambio de monedas virtuales deben comunicarse al fisco incluyéndolas en la declaración del Impuesto sobre la Renta de las Personas Físicas.

Una de las últimas consultas de la Hacienda Española, Consulta $N^{\circ}$ V1069-19 del 20 de mayo de 2019, está relacionada al criterio de vinculación de los bitcoin, así tenemos que la moneda virtual se encuentra situada en territorio español cuando en dicho territorio radique la entidad con la cual se realiza el servicio de almacenamiento de los bitcoin, ya que el acceso a ellos requerirá el acceso a la página web de la entidad administradora, con 
lo cual, se evidencia la necesaria participación de esta. En consecuencia, cuando se realice la transferencia de monedas virtuales situados en territorio español conforme al criterio antes mencionado, se entiende producida la ganancia patrimonial.

Como puede apreciarse la Autoridad Española ha emitido cierta directriz de la forma de tributar de las monedas virtuales, aunque aún sigue siendo poco clara para los usuarios de estos.

En Sudamérica hemos encontrado que Argentina realizó una modificación a la Ley de Impuesto a las Ganancias, mediante la Ley N ${ }^{\circ} 27430$ del 27 de diciembre de 2017, estableciendo que las ganancias derivadas de la venta de monedas digitales estarán gravadas con una tasa del 15\% (Congreso de la República del Perú, 2018). Asimismo, el tratamiento tributario de las criptomonedas corresponde al tratamiento de valores mobiliarios (Library of Congress s.f.).

En el caso de Colombia, la Dirección de Impuestos y Aduanas Nacionales, se pronunció mediante los Oficios ํo 20436 del 2 de agosto de 2017 y Nº00314 del 7 de marzo de 2018, estableciendo que el minado de monedas virtuales está gravado con el Impuesto a la Renta, tal como se aprecia a continuación:

"Acorde con lo expuesto, se puede concluir que las monedas virtuales no son dinero para efectos legales. No obstante, en el contexto de la actividad de minería, en tanto se perciben a cambio de servicios y/o comisiones, corresponden a ingresos y, en todo caso, a bienes susceptibles de ser valorados y generar una renta para quien las obtiene como de formar parte de su patrimonio y surtir efectos en materia tributaria.” (Centro Interamericano Jurídico, s.f.)

En el caso de Chile, el Servicio de Impuestos Internos, se pronunció a través del Ordinario № 963 del 14 de mayo de 2018, indicando que las operaciones de compraventa de bitcoin o de otros activos virtuales o digitales no están afectas al Impuesto del Valor Agregado establecido en el Decreto Ley $\mathrm{N}^{\circ}$ 825. Por otro lado, señala que la tributación de las utilidades generadas por la compra-venta de bitcoin o de otros activos virtuales o digitales se encuentra dentro del ámbito de aplicación de la Ley del Impuesto a la Renta. Asimismo, establece que podrá deducirse el costo directo generado por la adquisición de bitcoins o de otros activos virtuales o digitales cuya venta ha generado los ingresos brutos del ejercicio; los mencionados costos se acreditan con los comprobantes de transferencia electrónica o con las facturas de ventas no afectas a IVA. 


\subsubsection{Disposiciones normativas en el Perú}

En el Perú no existen disposiciones normativas tributarias especiales que regulen a las criptomonedas, asimismo, la Superintendencia Nacional de Aduanas y Administración Tributaria - SUNAT no ha emitido ningún pronunciamiento al respecto, en desmedro de la seguridad jurídica de los contribuyentes que realizan transacciones con criptomonedas y de la actividad recaudadora del estado.

En ese sentido, en el presente trabajo analizaremos qué disposiciones normativas tributarias generales resultan aplicables a las tres principales operaciones que derivan del uso del bitcoin, identificando la problemática que deriva de dicha aplicación y sustentando el porqué de la necesidad de una regulación especial para este tipo de activo intangible.

El estudio se centrará en las disposiciones relacionadas con el Impuesto a la Renta y a la imposición al consumo, específicamente en el Impuesto General a las Ventas; 


\section{CAPÍTULO II: LA IMPOSICIÓN A LAS GANANCIAS Y LAS CRIPTOMONEDAS - EL CASO DEL BITCOIN}

En este capítulo desarrollaremos la implicancia tributaria en la imposición a las ganancias de las operaciones con criptomonedas, especialmente en las que se emplean bitcoins. El análisis toma como premisa la naturaleza jurídico-económica de las criptomonedas identificada en el capítulo anterior.

Ahora bien, resulta pertinente precisar que el análisis de la incidencia tributaria que realizaremos se limitará a las operaciones con criptomonedas que se realizan con más frecuencia y que se detallan a continuación:

- La compra-venta de criptomonedas - bitcoins.

- Como medio de pago en las operaciones de adquisición de bienes (permuta) y contratación de servicios (pago en especie).

- La operación de minería de bitcoin (servicio de validación de operaciones de transferencia de bitcoins).

Pues bien, en el sistema tributario peruano, la imposición a la ganancia se efectúa a través del Impuesto a la Renta. Dicho impuesto grava la manifestación de riqueza de las personas que obtienen ganancias derivadas de sus actividades comerciales, profesión u oficio; en ese sentido, resulta de particular interés analizar si a la luz de nuestra normatividad, los bitcoins generan ganancias afectas al Impuesto a la Renta. 


\section{El Impuesto a la Renta en el Perú}

$\mathrm{Al}$ respecto, debemos mencionar que nuestra Ley del Impuesto a la Renta ${ }^{19}$ recoge tres teorías que fundamentan la imposición a las ganancias, estas son: la renta producto, flujo de riqueza y la del incremento patrimonial más consumo.

Lo postulado por estas tres teorías ha servido de base para las disposiciones establecidas en los artículos 1, 2 y 3 de la LIR. En efecto, de la revisión del artículo 1 de la norma antes citada se aprecia que, en nuestra legislación, el Impuesto a la Renta grava:

a) Las rentas que provengan del capital, del trabajo y de la aplicación conjunta de ambos factores, entendiéndose como tales aquellas que provengan de una fuente durable y susceptible de generar ingresos periódicos.

b) Las ganancias de capital.

c) Otros ingresos que provengan de terceros, establecidos por esta ley.

d) Las rentas imputadas, incluyendo las de goce o disfrute, establecidas por esta ley.

Asimismo, el artículo 1 de la norma citada establece que están incluidas dentro de las rentas previstas en el inciso a), las siguientes:

- Las regalías

- Los resultados de la enajenación de:

- Terrenos rústicos o urbanos por el sistema de urbanización o lotización.

- Inmuebles, comprendidos o no bajo el régimen de propiedad horizontal, cuando hubieren sido adquiridos o edificados, total o parcialmente, para efecto de la enajenación.

- Los resultados de la venta, cambio o disposición habitual de bienes.

19 Cuyo Texto Único Ordenado fue aprobado mediante Decreto Supremo No 179-2004-EF, publicado el 08.12.2004 y normas modificatorias. En adelante, LIR. 
Para efecto de esta investigación, analizaremos si las tres operaciones con bitcoins antes señaladas, se encuentran dentro del ámbito de aplicación de la LIR, para ello, debemos precisar que lo dispuesto en el inciso d) del artículo 1 de la LIR corresponde a rentas provenientes de actividades que expresamente se han consignado en la ley, por lo que su análisis no amerita mayor detenimiento, dado que ninguna de las operaciones a analizar se ha considerado como una renta imputada ${ }^{20}$. Asimismo, en relación a las rentas establecidas en el inciso c) del artículo 1 de la LIR, dado su carácter residual, cabe señalar que procederemos a revisar dicho supuesto de hecho solo si los ingresos provenientes de las operaciones que estudiaremos no responden a lo establecido en los incisos a) y b); en ese sentido, nos centraremos en revisar las teorías de rentas recogidas en los incisos a) y b) del artículo 1 de la LIR, denominadas renta producto y flujo de riqueza.

Sin perjuicio de lo antes señalado, mencionaremos que el tercer criterio de imputación regulada en la LIR es la teoría de incremento patrimonial en el cual lo relevante es la variación patrimonial del contribuyente en un período determinado, sin importar si existió una fuente durable o si hubo una transferencia de flujo de riqueza de parte de un tercero o si hubo ingresos realizados, lo que importa es que se aprecia el incremento o detrimento del patrimonio del individuo.

Cabe indicar que nuestra legislación recoge la teoría antes citada solo para determinados supuestos taxativamente señalados por dicha norma los cuales no son objeto del presente trabajo ${ }^{21}$.

En consecuencia, no amerita que analicemos la teoría de consumo más incremento patrimonial la cual está enfocada en el individuo y en la variación de su patrimonio en un período determinado.

20 En la LIR se ha dispuesto como renta imputada a la renta ficta proveniente de predios cuya ocupación hayan cedido sus propietarios gratuitamente o a precio no determinado.

21 Por ejemplo, nuestra norma señala que constituye renta gravada el resultado por exposición a la inflación determinado conforme a la legislación vigente. 


\subsection{Las rentas que provengan del capital, del trabajo y de la aplicación conjunta de ambos factores}

Mediante el inciso a) del artículo 1 de la LIR, nuestro legislador recoge la teoría de la renta producto, siendo lo relevante de dicha teoría, como lo postula García (1978), que se entiende como renta gravada "el producto periódico que proviene de una fuente durable en estado de explotación ${ }^{22}$ ".

En tal sentido, como señala Alva (2012), el producto debe ser identificable y distinto de la fuente de la que proviene $\mathrm{y}$, de otra parte, la fuente debe quedar en condiciones reales o potenciales de seguir produciendo rentas periódicamente.

Por su parte, Julio Fernández (2004), considera que "dicha fuente es un capital que puede ser corporal o incorporal". Ahora bien, la fuente productora puede estar constituida por un bien o una actividad humana que se realiza periódicamente y que bajo las condiciones dadas pueda generar ingresos que constituyan rentas gravadas.

Bravo Cucci (2002) señala que esta teoría proviene de una concepción económica de la renta y que las características básicas son: a) “(...) debe ser producto de una fuente; b) debe ser un producto periódico; c) tiene que provenir de una fuente que se mantenga en el tiempo; y, d) deja de producirse si se extingue la fuente que la genera".

Luego de haber expuesto los alcances de la teoría de renta producto, analizaremos si las operaciones con bitcoins materia de la presente investigación, corresponden ser gravadas bajo el sustento de esta teoría:

\section{Compra-venta de criptomonedas - bitcoins}

En Internet existen páginas web que alojan plataformas dedicadas a la compra-venta de bitcoins (también conocidas como exchanges), por medio de las cuales se realizan operaciones de compra-venta de criptomonedas a cambio de monedas de curso legal como el dólar o el sol o incluso por otras criptomonedas, es así que, por ejemplo, en el

22 La citada definición fue recogida por la Administración Tributaria en el Informe $N^{\circ}$ 318-2005SUNAT/2B0000. 
Perú encontramos plataformas web como Cambistabitcoin ${ }^{23}$, Bitinka ${ }^{24}$, Buda ${ }^{25}$ (antes SurBTC S.A.), Exchanger Perú ${ }^{26}$, entre otras.

Ahora bien, cabe señalar que en dichas plataformas también brindan servicios como por ejemplo el almacenamiento de criptomonedas o el servicio de intermediación mediante el cual contactan a usuarios (también conocidos como traders) que deseen vender sus criptomonedas con otros que quieren comprar dichos bienes, cobrando una comisión por la operación; sin embargo, como ya lo señalamos anteriormente, en esta investigación solo analizaremos la operación de compra-venta de criptomonedas y si los ingresos obtenidos por dicha actividad califican como renta gravable.

En ese contexto, consideramos que la comercialización de bitcoins sí responde al criterio de la teoría de renta producto, dado que en la referida actividad económica se aprecia que para obtener los ingresos, la actividad de compra-venta requiere de la conjunción del capital más trabajo, siendo que el capital estaría constituida por las criptomonedas que se constituyen como existencias, al ser bienes intangibles y, de otro lado, el trabajo estaría constituido por la actividad de intercambiar los bitcoins por una moneda de curso legal y viceversa, por lo que podemos afirmar que dicha actividad está comprendida dentro del ámbito de aplicación de la LIR.

Como se aprecia, la comercialización de bitcoin proviene de una fuente durable y susceptible de generar ingresos periódicos, en tanto siempre existe la posibilidad de realizar la actividad de compra-venta.

Lo antes señalado encuentra sustento en el criterio adoptado por la Administración Tributaria (2007), la que, salvando las diferencias ${ }^{27}$, citando a García Mullín señaló en su

23 Se autodenominan la primera plataforma peruana de compra-venta e intercambio de criptomonedas. Además, en dicha página web señala que cuenta con dos páginas webs dedicadas al mismo rubro: www.bitcoinenlinea.com/ y www.bitcoindelperu.com/.Recuperado de: www.cambistabitcoin.com/

24 En dicha plataforma se ofrece intercambio de bitcoins, ethereums dash, ripple y otras criptomonedas. Recuperado de: https://www.bitinka.com/es/bitinka/home/

25 Plataforma web que opera en Chile, Colombia, Perú y Argentina. Ofrece la compra-venta de criptomonedas. Recuperado de: https://www.buda.com/peru/

26 En su página web señalan que es un servicio de cambio de divisa soles/dólares y también un servicio de intercambio de monederos electrónicos. Además, señalan que también prestan servicios a aquellas personas que reciben sus honorarios por medio de monederos electrónicos y que desean cambiarlos por otros o por dinero en un banco peruano, así como también intercambiarlos por productos y/o servicios. Recuperado de: https://exchangerperu.com/

27 Toda vez que como lo hemos señalado, las criptomonedas no son reconocidas legalmente como divisas. 
Informe $\mathrm{N}^{\circ}$ 057-2017-SUNAT/5D0000 que las ganancias generadas por las operaciones de compra-venta de divisas se encuentran afectas al impuesto a la renta, toda vez que "los ingresos derivados de la actividad de compra-venta de moneda extranjera, realizadas por las empresas dedicadas a dicho rubro, provienen de una fuente durable en estado de explotación y susceptible de generar ingresos periódicos, por lo que se enmarcan dentro del criterio de renta producto, y también del flujo de riqueza”.

Por otro lado, en cuanto a la compra-venta de criptomonedas en la cual se intercambian bitcoins por otras criptomonedas como por ejemplo ripple, litecoin, ethereum, entre otras, nos preguntamos si en dicha operación estamos frente a un intercambio de bienes homogéneos o de bienes diferentes.

Sobre el particular, cabe mencionar que las diversas criptomonedas actuales se originan en diferentes protocolos informáticos, teniendo un ámbito de aceptación, características, valores, funcionalidades y denominación diferentes; con lo cual, se tratan de bienes que son diferentes. En tal sentido, el intercambio de criptomonedas por otras criptomonedas calificaría como una permuta de bienes, configurándose una doble transferencia de propiedad a las que se le deberá aplicar lo dispuesto en la LIR respecto del costo computable y el valor de los bienes que se intercambian y, como señala Medrano (2011), pudiendo generarse utilidad (o pérdida) por la diferencia entre el costo computable que tengan los bienes que se entregan y el valor de mercado de los bienes que se reciben (p. 320-327).

A modo ilustrativo de lo estudiado en el presente acápite, nos remitimos al siguiente ejemplo:

Tabla 2.1

Aplicación del Impuesto a la Renta a la compra-venta de criptomonedas

\section{Supuesto analizado:}

Una sociedad constituida en Perú se dedicada a intercambiar criptomonedas por moneda de curso legal u otras criptomonedas, a través de una plataforma de internet.

(continúa) 
(continuación)

\begin{tabular}{|l|l|}
\cline { 2 - 3 } \multicolumn{1}{c|}{} & \multicolumn{1}{c|}{ ¿Operación gravada? } \\
\hline Impuesto a la Renta & $\begin{array}{l}\text { Los ingresos obtenidos por la enajenación de bienes (bitcoins) } \\
\text { provienen de una fuente durable y susceptible de generar ingresos } \\
\text { periódicos. } \\
\text { En consecuencia, son operaciones que califican como renta } \\
\text { conforme a la teoría de renta producto, estando comprendidas } \\
\text { dentro del inciso a) del artículo 1 de la LIR. }\end{array}$ \\
\hline
\end{tabular}

Fuente: Elaboración propia

\section{Minería de bitcoin}

En cuanto a la operación de minería de bitcoins debemos recordar que dicha operación consiste en el servicio de validación de operaciones que involucran la transferencia de bitcoins, siendo que dicho servicio puede ser prestado desde cualquier parte del mundo y por cualquier usuario (node) conectado a la red bitcoin. Mediante la validación de las operaciones realizadas con el bitcoin, se otorga seguridad a los usuarios de que los bitcoins transados en la operación validada están siendo utilizados únicamente en dicha operación y como recompensa por la validación efectuada, a los mineros se les otorga una cantidad de bitcoins en calidad de comisión, la que se calcula en función a la cantidad de información validada, y además, una cantidad de bitcoins a manera de recompensa, los que fueron generados automáticamente por el sistema.

En la actividad descrita observamos que la fuente productora lo constituye la actividad llevada a cabo por el minero que valida las operaciones realizadas con bitcoins a través de ordenadores especializados que en primer lugar se encargan de hallar la solución al complejo problema matemático, para posteriormente agregar un nuevo bloque a la cadena de bloques (blockchain) de bitcoin con toda la información validada.

Pues bien, en este caso, el capital lo constituyen los antes referidos ordenadores especializados de minería de criptomonedas y por otro lado el trabajo lo constituye la actividad de los mineros quienes se ocupan del adecuado funcionamiento de los ordenadores, asegurarse de la provisión de la potencia eléctrica necesaria para el funcionamiento de los equipos, el mantenimiento de estos, entre otros. 
En virtud de lo expuesto, la actividad del minado de criptomonedas al efectuarse mediante la conjunción del capital y del trabajo, genera rentas que provienen de una fuente durable y susceptible de generar ingresos periódicos; en consecuencia, la referida actividad está gravada con el Impuesto a la Renta conforme a lo establecido en el inciso a) del artículo 1 de la LIR.

En ese contexto, cabe precisar que la minería de bitcoins realizada por una persona natural en ningún caso generarán rentas provenientes del trabajo, toda vez que las soluciones a los problemas matemáticos son halladas por los equipos informáticos especializados y no por la persona natural, en ese sentido, las rentas generadas no son obtenidas por el ejercicio de una profesión, arte, ciencia u oficio que calificarían como una renta de trabajo de conformidad con lo dispuesto en la LIR.

En consecuencia, la minería de bitcoin esencialmente es una actividad empresarial que genera rentas de tercera categoría, de conformidad con el artículo 28 de la LIR.

A modo ilustrativo de lo estudiado en el presente acápite, nos remitimos al siguiente ejemplo:

Tabla 2.2

Aplicación del Impuesto a la Renta a la minería de bitcoins

\section{Supuesto analizado:}

Una sociedad peruana se dedica a la minería de bitcoins obteniendo como recompensa nuevos bitcoins.

\begin{tabular}{|l|l|}
\cline { 2 - 3 } \multicolumn{1}{c|}{} & \multicolumn{1}{c|}{ ¿Operación gravada? } \\
\hline Impuesto a la Renta & $\begin{array}{l}\text { Los ingresos obtenidos por la minería de bitcoins provienen de una } \\
\text { fuente durable y susceptible de generar ingresos periódicos, } \\
\text { constituyendo una actividad empresarial que se encuentran } \\
\text { categorizadas como rentas de tercera categoría. } \\
\text { En consecuencia, son operaciones que califican como renta } \\
\text { conforme a la teoría de renta producto, estando comprendidas } \\
\text { dentro del inciso a) del artículo 1 de la LIR. }\end{array}$ \\
\hline
\end{tabular}

Fuente: Elaboración propia 


\section{Medio de pago}

La renta generada en las operaciones en las que se emplean criptomonedas como medio de pago a fin de intercambiarlas por bienes o servicios, no responden al criterio de la teoría renta producto, toda vez que al transferirse las criptomonedas se agota la fuente que generó la renta, no permitiendo un producto periódico y no manteniéndose en el tiempo la referida fuente; así las citadas operaciones no se encuentran gravadas por lo dispuesto en el inciso a) del artículo 1 de la LIR, sin embargo, corresponde analizar si estas podrían cumplir con el criterio de la teoría de flujo de riqueza que revisaremos en el siguiente acápite.

A modo ilustrativo de lo estudiado en el presente acápite, nos remitimos al siguiente ejemplo:

\section{Tabla 2.3}

Aplicación del Impuesto a la Renta a la utilización de las criptomonedas (bitcoins) como medios de pago

\section{Supuesto analizado:}

Una sociedad peruana adquiere bienes y/o servicios a través del pago con bitcoins, asimismo, admite las referidas criptomonedas en la venta de bienes y/o prestación de servicios a una persona jurídica y/o natural domiciliada en el país.

\begin{tabular}{|l|l|}
\cline { 2 - 3 } \multicolumn{1}{c|}{ ¿Operación gravada? } \\
\hline Impuesto a la Renta & $\begin{array}{l}\text { Los ingresos obtenidos por el intercambio de bitcoins por bienes y/o } \\
\text { servicios no encajan dentro de la teoría de renta producto porque al } \\
\text { transferirse el activo se agota la fuente, no obstante, dicha operación } \\
\text { se encuentra gravada a la luz de la teoría de flujo de riqueza }\end{array}$ \\
En el supuesto del intercambio de bitcoins por bienes constituye una \\
permuta de bienes. \\
En el supuesto del intercambio de bitcoins por servicios origina un \\
pago en especie.
\end{tabular}

Fuente: Elaboración propia 


\subsection{Las ganancias de capital}

El inciso b) del artículo 1 de la LIR establece que el Impuesto a la Renta grava la ganancia de capital y su artículo 2 establece que constituye ganancia de capital cualquier ingreso que provenga de la enajenación de bienes de capital y se entiende por bienes de capital a aquellos que no están destinados a ser comercializados en el ámbito de un giro de negocio o de empresa.

La segunda teoría recogida por el legislador es la denominada flujo de riqueza la cual, en palabras de García (1978), se entiende como renta la totalidad de los flujos provenientes de operaciones con terceros en un período determinado, dentro de estos se encontrarían las ganancias de capital, los ingresos por actividades accidentales, los ingresos eventuales e ingresos a título gratuito.

Cabe precisar que bajo este criterio constituye renta cualquier ganancia percibida por la empresa de parte de terceros no siendo necesario por tanto que se cumpla con el requisito de la durabilidad de la fuente y los ingresos periódicos que de ella se perciben como sucede con el criterio de renta producto, por lo tanto, el criterio de flujo de riqueza es de mayor amplitud y abarca mayor cantidad de ingresos a ser gravados.

En ese sentido, en lo que respecta al flujo de riqueza el penúltimo párrafo del artículo 3 de la LIR ha establecido que:

"En general, constituye renta gravada de las empresas, cualquier ganancia o ingreso derivado de operaciones con terceros, así como el resultado por exposición a la inflación determinado conforme a la legislación vigente".

Cabe mencionar que el legislador ha establecido como criterio de imposición de la renta empresarial el criterio de flujo de riqueza; en tal sentido constituye renta gravada de las empresas cualquier ganancia o ingreso derivado de las operaciones con criptomonedas.

Ahora bien, las criptomonedas como hemos revisado en el Capítulo I del presente trabajo, podrían utilizarse como medio de pago en las operaciones de adquisición de bienes y contratación de servicios, siempre que sean aceptados por las partes intervinientes, en ese sentido, una empresa podría adquirir bienes y/o contratar servicios 
a cambio de criptomonedas, así como aceptarlos como medio de pago por los bienes transferidos y/o servicios prestados.

Partiendo de la premisa que el bitcoin califica como bien mueble intangible, la adquisición y/o venta de bienes que realiza una empresa a cambio de criptmonedas constituye una permuta de bienes, produciéndose la enajenación de bienes según lo dispuesto por el artículo 5 de la $\operatorname{LIR}^{28}$.

En cuanto a la contratación y/o prestación de servicios que realiza una empresa a cambio de criptmonedas constituye un pago en especie (bitcoin), y no califica como permuta debido a que el artículo 1602 del Código Civil ${ }^{29}$ establece que "Por la permuta los permutantes se obligan a transferirse reciprocamente la propiedad de bienes", en el caso planteado no se transfiere recíprocamente la propiedad de bienes.

En el estudio realizado acerca de la naturaleza jurídica de las criptomonedas, revisamos que no constituyen medios de pago regulados dentro de nuestro ordenamiento jurídico, no obstante, es innegable que cada día crecen los negocios que los aceptan, de forma que no son obtenidas para fines de comercialización o de inversión.

En el supuesto antes descrito, se advierte que darle el tratamiento de permuta a los intercambios de bienes por criptomoneda implicaría gravarlas con el Impuesto a la Renta cada vez que se realice la transferencia de criptomonedas haciéndolas más gravosas.

En ese sentido, consideramos pertinente que haya una regulación que especifique el tratamiento de las criptomonedas cuando sean utilizadas como medio de pagos independientemente a que se encuentre en discusión la naturaleza jurídica de la misma, de forma que se otorgue seguridad jurídica a los contribuyentes en el tratamiento

28 Artículo 5.- Para los efectos de esta Ley, se entiende por enajenación la venta, permuta, cesión definitiva, expropiación, aporte a sociedades y, en general, todo acto de disposición por el que se transmita el dominio a título oneroso.

29 En aplicación de lo dispuesto en la Norma IX del último Texto Único Ordenado del Código Tributario (aprobado por el Decreto Supremo N. ${ }^{\circ}$ 133-2013-EF, publicado el 22.6.2013 y normas modificatorias), la cual dispone que en lo no previsto por este Código o en otras normas tributarias podrán aplicarse normas distintas a las tributarias siempre que no se les opongan ni las desnaturalicen. Supletoriamente se aplicarán los principios del Derecho Tributario, o en su defecto, los Principios del Derecho Administrativo y los Principios Generales del Derecho. 
tributario a efectos del Impuesto a la Renta y no se vean perjudicados por operaciones gravosas.

\section{Compra-venta de criptomonedas por Persona Natural}

Respecto a las personas naturales que no realizan actividad empresarial, la LIR ha establecido supuestos específicos en los cuales estará gravada la ganancia de capital generada por ella.

Así tenemos que en el último párrafo del artículo 2 de la LIR dispone que:

"No constituye ganancia de capital gravable por esta Ley, el resultado de la enajenación de los siguientes bienes, efectuada por una persona natural, sucesión indivisa o sociedad conyugal que optó por tributar como tal, que no genere rentas de tercera categoría (...): i) Inmuebles ocupados como casa habitación del enajenante. ii) Bienes muebles, distintos a los señalados en el inciso a) de este artículo.”

Por su parte, el segundo párrafo de la norma citada señala que:

"Entre las operaciones que generan ganancias de capital, de acuerdo a esta Ley, se encuentran: a) La enajenación, redención o rescate, según sea el caso, de acciones y participaciones representativas del capital, acciones de inversión, certificados, títulos, bonos y papeles comerciales, valores representativos de cédulas hipotecarias, certificados de participación en fondos mutuos de inversión en valores, obligaciones al portador u otros valores al portador y otros valores mobiliarios."

En tal sentido, las personas naturales que hayan adquirido bitcoins con fines especulativos y que en algún momento decidan enajenarlos obteniendo con ello ganancia, estarían gravados en la medida que se encuentren dentro del inciso a) del artículo 2 de la LIR.

En este punto debemos mencionar que, según se analizó en el Capítulo 1 del presente trabajo de investigación, los bitcoin son bienes muebles según el artículo 886 del Código Civil. No obstante, no son acciones o participaciones representativas de capital, ni acciones de inversión, certificados, títulos, bonos y papeles comerciales, valores representativos de cédulas hipotecarias, certificados de participación en fondos mutuos de inversión en valores, obligaciones al portador u otros valores al portador. 
Asimismo, tampoco podríamos calificarlo como valor mobiliario debido a que no cumplen con las características establecidas en el artículo 3 de la Ley de Mercado de Valores y el artículo 225 de la Ley de Títulos Valores, como hemos revisado en el Capítulo 1 del presente trabajo de investigación.

De lo expuesto, concluimos que los bitcoins son bienes muebles distintos a los señalados en el inciso a) del artículo 2 de la LIR, por lo tanto, los ingresos derivados de la venta de bitcoins por persona natural que no realiza actividad empresarial, no constituyen ganancia de capital gravable para efecto de la Ley.

Como puede apreciarse, en la medida que no haya una modificación de la LIR incluyendo expresamente como ganancias de capital generadas por una persona natural la venta de bitcoin, consideramos que se encuentran fuera del ámbito de aplicación de la norma. A modo ilustrativo de lo estudiado en el presente acápite, nos remitimos al siguiente ejemplo:

\section{Tabla 2.4}

Aplicación del Impuesto a la Renta a compra-venta de criptomonedas realizada por personas naturales

\section{Supuesto analizado:}

Una persona natural sin negocio intercambia criptomonedas por moneda de curso legal u otras criptomonedas, recurriendo a las plataformas de internet que ofrecen la intermediación entre el vendedor y comprador a cambio de una comisión.

\begin{tabular}{|l|l|}
\cline { 2 - 3 } \multicolumn{1}{c|}{} & \multicolumn{1}{c|}{ ¿Operación gravada? } \\
\hline Impuesto a la Renta & $\begin{array}{l}\text { Los ingresos obtenidos por la enajenación de bienes (bitcoins) } \\
\text { constituyen renta según la teoría de flujo de riqueza. No obstante, } \\
\text { nuestro legislador ha decido gravar solo la enajenación de bienes } \\
\text { muebles detallados en el inciso a) del artículo } 2 \text { de la LIR. } \\
\text { En consecuencia, los bitcoin al no ser acciones, títulos valores, } \\
\text { valores mobiliarios, entre otros., no se encuentran gravadas con el } \\
\text { Impuesto a la Renta, de conformidad con el último párrafo del } \\
\text { artículo } 2 \text { de la LIR. }\end{array}$ \\
\hline
\end{tabular}

Fuente: Elaboración propia 
De todo lo expuesto, podemos afirmar que para efecto de la LIR la comercialización o intercambio de las criptomonedas -bitcoins- se encuentra dentro del ámbito de aplicación de la norma debido a que consideramos que la renta generada cumple con los criterios de las teorías de renta producto y flujo de riqueza. 


\section{CAPÍTULO III: LA IMPOSICIÓN AL CONSUMO Y LAS CRIPTOMONEDAS - EL CASO DEL BITCOIN}

Partiendo de la naturaleza jurídico-económica de las criptomonedas ensayada y propuesta en el presente trabajo de investigación, en particular la del bitcoin, en este capítulo revisaremos las implicancias tributarias dentro del ámbito de aplicación de la imposición que grava el consumo en el país.

Además, como se realizó en el capítulo anterior, para efectuar el análisis de la incidencia tributaria propuesto en el párrafo precedente, nos limitaremos a revisar las principales operaciones en las que se emplean los bitcoins y que se detallan a continuación:

- La compra-venta de criptomonedas - bitcoins.

- Como medio de pago en las operaciones de adquisición de bienes (permuta) y contratación de servicios (pago en especie).

- La operación de minería de bitcoin (servicio de validación de operaciones de transferencia de bitcoins).

Por lo que, a fin de abordar el tema propuesto, describiremos cómo se ha estructurado la imposición al consumo en el país de conformidad con la normativa vigente, lo que nos llevará a ensayar el tratamiento tributario aplicable a las operaciones donde se emplean las criptomonedas - bitcoins detalladas anteriormente, identificando la problemática que se genera en aplicación de la normativa vigente.

Ahora bien, la fuente de financiamiento de los gobiernos por excelencia es la recaudación de impuestos, la cual sienta sus bases en la capacidad contributiva del ciudadano. Dicha capacidad se aprecia en la disposición de riqueza que manifiesta el contribuyente al realizar consumos. Bajo esa premisa es que se ha estructurado en el país, dos impuestos que gravan la manifestación de riqueza que se evidencia en el consumo que realiza el ciudadano: el Impuesto General a las Ventas (IGV) y el Impuesto Selectivo al Consumo (ISC). 
Como señala Alva Matteucci (2013), el IGV es un impuesto de carácter general, plurifásico y no acumulativo, estructurado sobre la técnica del valor agregado que grava todas las fases del ciclo de producción y distribución hasta llegar al consumidor final, gravando solo el valor que se agrega en cada etapa, dado que en la etapa anterior ya se tributó.

Por su parte Villanueva (2009) señala que el ISC recae sobre determinados consumos, los suntuosos o de lujo o el consumo de bienes no esenciales. Este último, es un impuesto específico que se aplica en una sola etapa del ciclo de producción del bien afecto o algunas veces en dos etapas cuando el bien proviene del extranjero, dado que se grava la importación, ya sea para auto consumo o comercialización, así como la posterior venta en el país.

El IGV e ISC, actualmente, están regulados por las mismas normas, el Decreto Legislativo $\mathrm{N}^{\mathrm{o}} 821^{30}$ y su reglamento. Ahora bien, dada la naturaleza del ISC, al gravar solo las operaciones de venta en el país y la importación de determinados bienes listados en los Apéndices III y IV del citado decreto legislativo, así como actividades de juegos de azar, no resulta relevante el ahondar más en el análisis de dicho impuesto, toda vez que al no encontrarse las criptomonedas listadas en los aludidos apéndices, solo se puede concluir que las operaciones que emplean criptomonedas que se estudian en el presente trabajo de investigación, no estarán gravadas con dicho impuesto; en ese sentido, el análisis de la imposición al consumo, se centrará en el IGV.

\section{El Impuesto al Valor Agregado - Impuesto General a las Ventas:}

El artículo 1 de la Ley del IGV establece que dicho impuesto grava las siguientes operaciones:
a) La venta en el país de bienes muebles;
b) La prestación o utilización de servicios en el país;
c) Los contratos de construcción;

30 Publicado el 23.4.1996, cuyo Texto Único Ordenado fue aprobado mediante Decreto Supremo No 055 99-EF, publicado el 15.4.1999 y normas modificatorias, en adelante la Ley del IGV. 
d) La primera venta de inmuebles que realicen los constructores de los mismos.

e) La importación de bienes.

Ahora bien, atendiendo a la naturaleza de los bitcoins, podemos afirmar de manera categórica que ninguna de las tres operaciones que emplean la referida criptomoneda que son materia de análisis en esta investigación, se encuentran afectos con el IGV por lo dispuesto en los incisos c) y d) del artículo 1 de la citada ley, toda vez que la compraventa, uso como forma de pago o la minería de bitcoins no califican como una actividad que pueda ser catalogada como una de construcción de acuerdo a la Clasificación Internacional Industrial Uniforme de las Naciones Unidas.

De acuerdo a lo antes expuesto, analizaremos los otros tres supuestos de hecho por los que las operaciones en las que medien los bitcoins podrían estar gravadas dada su naturaleza jurídico-económica de bien intangible.

\subsection{La venta en el país de bienes muebles}

A fin de entender de forma clara lo que comprende el supuesto de hecho descrito en el inciso a) del artículo 1 de la Ley del IGV, resulta necesario comprender lo que debemos entender por venta y por bien mueble y para ello, en la Ley del IGV se han desarrollado las definiciones para efectos de la aplicación del impuesto, siendo que dichas definiciones, en atención del principio de especialidad ${ }^{31}$, se apartan de lo dispuesto en la legislación general.

En ese orden de ideas, la definición de venta contemplada en el inciso a) del artículo 3 de la Ley del IGV, dispone que se entiende por venta a todo acto por el que se transfieren bienes a título oneroso, independientemente de la designación que se dé a los

31 Principio que postula como regla en la aplicación del derecho que la norma especial prima sobre la norma general. Para Zegarra (2005), cuando existe un conflicto normativo, en aplicación de este principio, para preferir una norma jurídico tributaria sobre otra, se debe realizar un análisis exclusivamente jurídico, sin consideraciones adicionales subjetivas o que involucren otras áreas del saber (Zegarra J., 2005). 
contratos o negociaciones que originen esa transferencia y de las condiciones pactadas por las partes.

Además, en dicha definición también se señala que se encuentran comprendidas las operaciones sujetas a condición suspensiva en las cuales el pago se produce con anterioridad a la existencia del bien.

Por su parte, en el numeral 3 del artículo 2 del Reglamento de la Ley del Impuesto General a las Ventas e Impuesto Selectivo al Consumo ${ }^{32}$, se complementa la definición de venta referida en los párrafos precedentes, señalando que se considera venta a los actos que conllevan la transmisión de propiedad de bienes, encontrándose comprendidos entre estos, la venta propiamente dicha, permuta, dación en pago, expropiación, adjudicación por disolución de sociedades, aportes sociales, adjudicación por remate o cualquier otro acto que conduzca al mismo fin.

Además, en el literal a) del numeral 1 del artículo 2 del Reglamento de la Ley del IGV, se precisa que en la operación gravada de venta en el país de bienes muebles recogida en el artículo 1 de la Ley del IGV, está comprendida la venta de bienes muebles ubicados en el territorio nacional, que se realice en cualquiera de las etapas del ciclo de producción y distribución, sean estos nuevos o usados, independientemente del lugar en que se celebre el contrato o del lugar en que se realice el pago. Agrega que tratándose de bienes intangibles se consideran ubicados en el territorio nacional cuando el titular y el adquirente se encuentran domiciliados en el país.

Pues bien, expuesta la regulación del IGV, corresponde analizar en qué operaciones donde se emplean los bitcoins se realiza el supuesto de hecho descrito en el inciso a) del artículo 1 de la Ley del IGV:

- La compra-venta de bitcoins: Consideramos que esta es la operación por excelencia en la que se cumple con el supuesto de hecho de la hipótesis de incidencia, toda vez que esta operación involucra la transferencia de propiedad onerosa de las criptomonedas que se emplean en la operación.

32 Aprobado mediante Decreto Supremo N 029-94-EF, publicado el 29.3.1994 y normas modificatorias. En adelante el Reglamento de la Ley del IGV. 
- Como forma de pago: Teniendo en cuenta que al emplear bitcoins para adquirir bienes se produce una permuta ${ }^{33}$ y si se emplean para contratar servicios se produce un pago en especie, en ambos casos se realiza la transferencia de propiedad onerosa de las criptomonedas que se emplean en la operación.

- La operación de minería bitcoin: Definitivamente no, dado que esta operación consiste en la prestación de un servicio, por tanto, al no haber la transferencia de propiedad de un bien mueble, en ningún caso podría calificar como una venta.

Ahora bien, con la finalidad de poder determinar que las operaciones con criptomonedas que califican como venta se encuentran gravadas con el IGV, debemos analizar si los bitcoins como criptomonedas califican como bienes muebles, puesto que, de no calificar como tal, las referidas operaciones con criptomonedas no estarían gravadas.

$\mathrm{Al}$ respecto, el inciso b) del artículo 3 de la Ley del IGV define como bien mueble a los bienes corporales que pueden llevarse de un lugar a otro, a los derechos referentes a los mismos, a los signos distintivos, invenciones, derechos de autor, derechos de llave y similares, a las naves y aeronaves, así como los documentos y títulos cuya transferencia implique la de cualquiera de los mencionados bienes.

Por su parte, el numeral 8 del artículo 2 del Reglamento de la Ley del IGV señala que no se consideran bienes muebles a la moneda nacional, la moneda extranjera, ni cualquier documento representativo de éstas; las acciones, participaciones sociales, participaciones en sociedades de hecho, contratos de colaboración empresarial, asociaciones en participación y similares, facturas y otros documentos pendientes de cobro, valores mobiliarios y otros títulos de crédito salvo que la transferencia de los valores mobiliarios, títulos o documentos implique la de un bien corporal.

33 Cabe señalar que el inciso a) del numeral 4 del artículo 5 del Reglamento de la Ley del IGV establece que en el caso de permuta de bienes muebles o inmuebles se considerará que cada parte tiene carácter de vendedor y la base imponible de cada venta afecta estará constituida por el valor de venta de los bienes comprendidos en ella de acuerdo al valor de mercado que se determine de la aplicación de las normas del Impuesto a la Renta. 
Pues bien, cabe señalar que los bitcoins como bienes intangibles entra en la ya conocida controversia del ámbito de aplicación del IGV, dado que al haberse incluido el término de bienes "similares", se origina el debate acerca del alcance de dicho término. $\mathrm{Al}$ respecto, existen tres posiciones respecto de esta controversia:

- La de la Administración Tributaria e inicialmente compartida por el Tribunal Fiscal en su Resolución $N^{\circ}$ 2424-5-2002 mediante la cual se adopta como criterio que por el término similar, la norma hace referencia a los bienes que mantienen la naturaleza de bien mueble de acuerdo a la legislación común, siendo que al recurrir a esta, se consideran bienes muebles todos los que no son considerados como inmuebles ${ }^{34-35}$.

- La posición de expertos como Villanueva Gutiérrez (2009) que sostiene que la norma vigente del IGV al momento de calificar como bienes muebles a los intangibles no hace referencia a ellos de manera general, solo se ha limitado a considerar a los signos distintivos, invenciones, derechos de autor, derechos de llave y similares ${ }^{36}$.

- Por último, una posición más acotada aún, es la sostenida por expertos como Córdova Arce (2004), que postula que la interpretación de la norma debe partir de un análisis gramatical, por lo que al haberse consignado el término "similares" seguido del de "derechos de llave" unido por la conjunción "y", solo se debe entender que los bienes intangibles considerados como bienes muebles afectos al IGV son aquellos que sean similares a los derechos de llave.

Con la finalidad de comprender las posiciones que difieren de la sostenida por la Administración Tributaria, resulta necesario revisar algunas nociones básicas de los

34 La legislación común aplicable se encuentra regulada por el artículo 886 del Código Civil, que establece en su numeral 10 que son bienes muebles los demás bienes no comprendidos en el artículo 885, el cual enumera taxativamente los bienes inmuebles, no encontrándose en ese listado los bienes virtuales como los bitcoins.

35 Dicho criterio también ha sido recogido en las RTF N ${ }^{\circ}$ 7449-2-2003 y 2983-2-2004, entre otras.

36 Precisa que el aludido término debe ser entendido respecto de los intangibles listados en el inciso b) del artículo 3 de la citada norma, toda vez que se vulneraría el principio de legalidad si es que la interpretación del término similares se extendería a todo tipo de bienes intangibles. 
intangibles descritos expresamente en la norma y determinar si las criptomonedas se encuentran incluidas en ellos:

\section{- Signos Distintivos}

A pesar de que no hay una definición per se en una norma legal, las principales disposiciones legales se encuentran recogidas en la Decisión $\mathrm{N}^{\circ} 486$ de la Comisión de la Comunidad Andina que regula el Régimen Común sobre Propiedad Industrial de la Comunidad Andina y el Decreto Legislativo $\mathrm{N}^{\circ} 1075^{37}$.

Por su parte, en la Resolución del Tribunal Fiscal (RTF) $\mathrm{N}^{\circ}$ 2424-5-2002, el Tribunal Fiscal definió a los signos distintivos como los derechos de propiedad industrial adquiridos por su registro o por su uso, cuya finalidad, es la diferenciación en el mercado de los productos o servicios que se comercializan, o la identificación de una persona en el ejercicio de su actividad económica como las marcas, lemas comerciales, nombres comerciales, etc.

En ese sentido, atendiendo a la definición señalada por el citado órgano colegiado, los bitcoins no califican como un signo distintivo, dado que en ninguno de sus usos se emplea para diferenciar producto o servicio alguno en el mercado.

\section{- Derechos de Autor}

Regulada por el Decreto Legislativo $\mathrm{N}^{\circ} 822$ que aprueba la Ley sobre el Derecho de Autor $^{38}$, de la cual se desprende que el derecho de autor otorga la titularidad originaria de un derecho exclusivo y oponible a tercero, que compre a su vez, los derechos de orden moral y patrimonial (Córdova A., 2004).

Resulta pertinente señalar que en el numeral 34 del artículo 2 de la citada norma, se incluye a los programa de ordenador (software ${ }^{39}$ ) como creación generadora de

37 Decreto Legislativo que aprueba Disposiciones Complementarias a la Decisión $\mathrm{N}^{\circ} 486$ de la Comisión de la Comunidad Andina que establece el Régimen Común sobre Propiedad Industrial, publicado el 28.6.2008.

38 Publicado el 24.4.1996 y normas modificatorias. Derogado en la parte que se oponga a la Ley $\mathrm{N}^{\circ} 28131$ Ley del Artista Intérprete y Ejecutante, publicada el 19.12.2003.

39 Definido como la expresión de un conjunto de instrucciones mediante palabras, códigos, planes o en cualquier otra forma que, al ser incorporadas en un dispositivo de lectura automatizada, es capaz de hacer que un computador ejecute una tarea u obtenga un resultado. La protección del programa de ordenador comprende también la documentación técnica y los manuales de uso. 
derechos de autor, los mismos que pueden ser materia de enajenación, por lo tanto afectos al IGV.

En este contexto, cabe señalar que las criptomonedas no califican como un software, toda vez que atendiendo a la definición contenida en la Ley sobre el Derecho de Autor, este intangible no es capaz de hacer que un computador ejecute una tarea u obtenga un resultado, por lo tanto, podemos concluir que las operaciones en las que se emplean criptomonedas estudiadas en la presente investigación, no involucran la transferencia de derecho de autor de software.

\section{- Invención}

El artículo 3 del Decreto Legislativo $\mathrm{N}^{\circ} 1075$, establece que constituye elemento de la propiedad industrial, entre otros, la patente de invención, ya sea esta una invención de producto o procedimiento, sin distinción del campo de tecnología al que pertenezca, siempre que sea nueva, tenga nivel inventivo y sea susceptible de aplicación industrial.

De acuerdo a esta definición, el bitcoin al día de hoy tampoco calificaría como invención, toda vez que la primera criptomoneda creada data del 2009, siendo que todas las creadas posteriormente no implican una nueva creación intelectual por tratarse del mismo bien creado en el 2009.

\section{- Derecho de llave}

Actualmente, no se encuentra una definición de este derecho en norma alguna, no obstante, la Administración Tributaria $(2007,2010)$ en los Informes $\mathrm{N}^{\circ}$ 213-2007SUNAT/2B0000 y 146-2010-SUNAT/2B0000, citando a Picón, señaló qué debe entenderse por derecho de llave; así, el citado derecho viene a ser el privilegio que la empresa mantiene sobre la clientela, es decir, el valor de traspaso de la clientela existente de una empresa, ya que mientras el goodwill es ese valor superior que tiene una empresa sobre el valor real de sus activos y pasivos, el derecho de llave es parte integrante de este valor, en consecuencia forma parte del goodwill de una empresa.

En este contexto el bitcoin, tampoco puede ser calificado como un derecho de llave, toda vez que la transferencia de bitcoins no implica la transferencia del valor de una empresa respecto de su clientela. 
De lo antes expuesto, manteniendo una posición conservadora, podemos concluir que tanto las operaciones de compra-venta de bitcoins y en las que se emplean como un medio de pago, al implicar la transferencia de propiedad de las referidas criptomonedas, califican como ventas gravadas con el IGV, de conformidad con lo dispuesto en el inciso a) de la Ley del IGV.

\subsection{La prestación o utilización de servicios en el país}

De manera similar al análisis efectuado en el punto anterior, a fin de determinar si las operaciones con criptomonedas estudiadas en la presente investigación se encuentran dentro del ámbito de aplicación del IGV por lo establecido en el inciso b) del artículo 1 de la Ley del IGV, llevaremos a cabo el ejercicio de definir qué se debe entender por prestación o utilización de servicios en el país de conformidad con lo dispuesto en la Ley de IGV, para lo cual desarrollaremos las definiciones pertinentes que resulten aplicables a las operaciones materia de estudio.

Ahora bien, el numeral 1) del inciso c) del artículo 3 de la Ley de IGV define al servicio como toda prestación que realiza una persona para otra y por la cual percibe una retribución o ingreso que se considere renta de tercera categoría para los efectos del Impuesto a la Renta, incluso si el prestador del servicio no se encuentra afecto a este último impuesto. También se considera servicio al arrendamiento de bienes muebles e inmuebles y al arrendamiento financiero. La retribución o ingreso también comprenden los montos que se perciban por concepto de arras, depósito o garantía y que superen el límite establecido en el Reglamento.

Agrega dicho dispositivo que el servicio es prestado en el país cuando la persona quien lo presta se encuentra domiciliado en él para efecto del Impuesto a la Renta, sea cual fuere el lugar de celebración del contrato o del pago de la retribución, mientras que el servicio será utilizado en el país cuando siendo prestado por un sujeto no domiciliado, es consumido o empleado en el territorio nacional, independientemente del lugar en que se pague o se perciba la contraprestación y del lugar donde se celebre el contrato.

De la definición antes señalada, se colige que, de las tres operaciones estudiadas en esta investigación, solo la operación de minería de bitcoins puede ser catalogada como una prestación o utilización de servicios en el país, dado que en las otras dos se efectúa 
una transferencia de propiedad de bienes que indubitablemente no califica como un servicio por lo que no se encuentran dentro del ámbito de aplicación del IGV por lo dispuesto en el inciso b) del artículo 1 de la Ley del IGV.

Teniendo en cuenta que la minería de bitcoins consiste básicamente en la validación de las operaciones con bitcoins realizadas, es decir las operaciones de compraventa de bitcoins o en las que se emplean los bitcoins como medio de pago. Dicha validación consiste en la realización de cálculos matemáticos realizados a través de un software y empleando equipos informáticos ${ }^{40}$ que concluyen con una solución que será registrada en un bloque (block), el que pasa a formar parte de la cadena de bloques (blockchain) del sistema bitcoin (Nakamoto, 2008).

De lo antes señalado, podemos afirmar que la acción de validar las operaciones es una prestación de hacer, sin embargo, esto no significa que podamos afirmar que estamos frente a un servicio gravado con el impuesto, toda vez que debemos comprobar que se cumplan con las demás condiciones establecidas en la norma como el que el servicio se realice a favor de otra persona y por la cual se perciba una retribución o ingreso que se considere renta de tercera categoría para los efectos del Impuesto a la Renta; asimismo, se debe observar la ubicación de las partes que participan en la operación, toda vez que esta determina si estamos frente a un servicio prestado o utilizado en el país o fuera del territorio nacional. Dichas condiciones serán evaluadas a continuación:

\section{- La minería de bitcoins como prestación realizada a favor de otra persona}

La definición de servicio contenida en la Ley del IGV exige que para que un servicio se encuentre gravado, este debe ser realizado estrictamente a favor de una persona distinta a quien la presta, es decir que exista una bilateralidad en la operación.

Pues bien, el servicio que se presta mediante la minería de bitcoins se realiza inicialmente a favor de las personas que han llevado a cabo una transacción con la finalidad de transferir la propiedad de los bitcoins como resultado de la operación de compra-venta o al haberse empleado como forma de pago y en segundo lugar al propio

40 Se emplean los procesadores de las computadoras tradicionales, procesadores de tarjetas gráficas o de equipos especializados para minería de criptomonedas. 
sistema de la criptomoneda y los usuarios de este por la validación y registro de información que otorga la seguridad al sistema. Lo antes señalado, se sustenta en que los beneficiarios del servicio de validación de la operación son las personas que realizaron precisamente la operación con bitcoins validada, dado que, con la inscripción de la información en el bloque, pueden verificar que los bitcoins fueron efectiva y válidamente transferidos del emisor al destinatario correspondiente; y en segundo lugar el sistema de bitcoins y sus usuarios dado que la información registrada en la cadena de bloques mantiene la operatividad del sistema generando la confianza en el mismo por la transparencia y la descentralización de su control.

\section{- La minería de bitcoins como servicio por el que se percibe una retribución o ingreso}

De conformidad con lo dispuesto en la Ley del IGV, para que una operación califique como un servicio afecto al impuesto, debe ser prestado a título oneroso, esto es, percibir una retribución o ingreso a cambio de la prestación del servicio.

Ahora bien, de acuerdo a lo expuesto en el primer capítulo, en las operaciones de minería de bitcoins se pueden percibir hasta dos ingresos: el primero que comprende de una comisión por la validación de la transacción y el segundo y más lucrativo, la generación (emisión) de nuevos bitcoins provenientes de crear válidamente un bloque con la información de las operaciones confirmadas.

Pues bien, sin perjuicio de que en la prestación del servicio de minería de bitcoins se percibe un ingreso, resulta necesario analizar si este tipo de ingresos son los que la norma exige para que el servicio esté gravado con el impuesto al consumo.

En ese sentido, atendiendo a lo postulado por Villanueva (2009), los servicios solo constituyen hipótesis de imposición cuando sean ejecutados a título oneroso, concretamente, cuando se ejecuten en correspondencia a una contraprestación. (Villanueva W., 2009).

Por su parte en la RTF $\mathrm{N}^{\circ}$ 1651-5-2004, el órgano colegiado ha señalado que los contratos onerosos son aquellos en los cuales cada una de las partes sufre un sacrificio que se compensa con una ventaja. 
En ese orden de ideas, podemos afirmar que el ingreso por las comisiones percibidas en las operaciones de validación de las transacciones con bitcoins, califica como una retribución, evidenciándose que la prestación del servicio del minero es a título oneroso, dado que este sufre un sacrificio (los costos de la prestación del servicio de validación) a cambio de una ventaja (la comisión obtenida) así como la parte que requiere la validación que también sufre un sacrificio (la comisión entregada) que se compensa con una ventaja (la validación de su operación con bitcoins).

Por otro lado, en cuanto a los bitcoins que el minero recibe como recompensa al obtener primero la solución al problema matemático y la consecuente creación y adhesión de un nuevo bloque a la cadena de bloques con la información de las operaciones realizadas con criptomonedas, no calificarían como una retribución del servicio de conformidad con lo dispuesto por la Ley del IGV, toda vez que no corresponde a una prestación a título oneroso ya que solo la parte que presta el servicio (el minero) es quien sufre un sacrificio (los costos de la prestación del servicio de validación) y recibe una ventaja (la recompensa de bitcoins) mientras que la otra no sufre el sacrificio porque los nuevos bitcoins que obtendrá el minero como recompensa, no provienen de su patrimonio sino que son liberados y puestos a disposición por parte del propio sistema bitcoin.

\section{- La minería de bitcoins como servicio por el que se percibe una retribución o ingreso que califica como renta de tercera categoría para efectos del Impuesto a la Renta}

De conformidad con lo dispuesto en la Ley del IGV, tenemos que como última condición que un servicio debe cumplir para estar gravado con el impuesto es que la retribución que se percibe a cambio de la prestación del servicio califique como renta de tercera categoría para efectos del Impuesto a la Renta ${ }^{41}$, aun cuando el sujeto que la perciba no se encuentre afecto a dicho impuesto.

Al respecto, como ya hemos señalado en el capítulo anterior, este servicio califica como una renta empresarial, esto es una renta de tercera categoría según lo establecido en

41 La referida calificación debe ser de manera objetiva, debiendo calificar como una renta empresarial bajo cualquiera de las teorías impositivas de renta, ya sea la renta producto, flujo de riqueza o la de incremento patrimonial más consumo. 
la Ley del Impuesto a la Renta, toda vez que en el desarrollo de la actividad económica de minería de bitcoins, se observa la conjunción de capital (constituida por los equipos informáticos con los que se realizan los cálculos matemáticos) y trabajo (constituido por la preparación y puesta en funcionamiento de los equipos informáticos así como su mantenimiento), calificando como rentas empresariales, es decir rentas de tercera categoría para efectos del Impuesto a la Renta.

Pues bien, en ese orden de ideas, solo se encuentra gravada la operación de minería de bitcoins por la cual se presta el servicio de validación de las operaciones con bitcoins por las cuales se perciba una comisión.

\section{- La ubicación de las partes que participan en la prestación de minería de bitcoins}

Por último, para que un servicio califique como operación gravada con el IGV, resulta necesario que este se preste o utilice en el país, para lo cual debemos determinar cuando suceden ambas situaciones.

Pues bien, para el caso de la prestación de servicios en el país, el segundo párrafo del numeral 1 del inciso c) del artículo 3 de la Ley del IGV establece que se deberá entender que el servicio es prestado en el país cuando el sujeto que lo presta se encuentra domiciliado en él para efecto del Impuesto a la Renta, sea cual fuera el lugar de celebración del contrato o del pago de la retribución. Ahora bien, el numeral 2 del artículo 2 del Reglamento de la Ley del IGV dispone que un sujeto es domiciliado en el país cuando reúna los requisitos establecidos en la Ley del Impuesto a la Renta ${ }^{42}$.

Sin perjuicio de lo antes señalado, cabe indicar que en el caso en que el usuario del servicio de validación no sea domiciliado en el país y el aprovechamiento del servicio tenga lugar en el exterior, estaremos frente a una exportación de servicios, siempre y cuando se cumplan los demás requisitos establecidos en la Ley del $\mathrm{IGV}^{43}$, por lo que de ser así, dicha operación no se encontrará gravada con el impuesto.

42 En los artículos 7 y 8 de la citada norma, así como en el 4 de su reglamento, se ha regulado los supuestos y requisitos para considerar domiciliada en el país a una persona natural y/o jurídica.

43 El artículo 33 de la Ley del IGV establece que la exportación de servicios no está afecta al impuesto. Además, establece que los servicios se considerarán exportados cuando cumplan concurrentemente con los siguientes requisitos: 
En ese contexto, la actividad de minado de bitcoins califica como una prestación de servicios gravada con el IGV, siempre que quien lo preste se encuentre domiciliado en el país y el usuario que lo recibe, lo aproveche en el territorio nacional, de lo contrario estaremos frente a una exportación de servicios inafecta del impuesto.

Por otro lado, en relación a la utilización de servicios en el país, el tercer párrafo del numeral 1 del inciso c) del artículo 3 de la Ley del IGV dispone que un servicio es utilizado en el país cuando siendo prestado por un sujeto no domiciliado, es consumido o empleado en el territorio nacional, independientemente del lugar en que se pague o perciba la contraprestación y del lugar donde se celebre el contrato.

A mayor abundamiento, cabe indicar que la Administración Tributaria (2004) en su Informe $\mathrm{N}^{\circ} 228$-2004-SUNAT/2B0000 establece como criterio que para determinar si el servicio prestado por un no domiciliado ha sido consumido o empleado en el territorio nacional, deberá atenderse al lugar en que se hace el uso inmediato o el primer acto de disposición del servicio. Para ello deberá analizarse las condiciones contractuales que han acordado las partes a fin de establecer dónde se considera que el servicio ha sido consumido o empleado. Además, en dicho informe, la Administración Tributaria citando al Tribunal Fiscal, señala que el modo de establecer si un servicio es utilizado en el país, es decir, si es consumido o empleado en el territorio nacional, es en función del lugar donde el usuario del servicio lleva a cabo el primer acto de disposición del mismo ${ }^{44}$, esto es, el lugar en donde se disfrute del resultado del servicio, por lo que para que se determine que el servicio de minado es una operación afecta con el impuesto, el referido lugar debe ser dentro del territorio nacional.

De lo antes señalado, se colige que la actividad de minería de bitcoins prestada por un sujeto no domiciliado calificará como una utilización de servicios en el país cuando el usuario aproveche el servicio de validación de operaciones con bitcoins realizadas en el territorio nacional.

\footnotetext{
a) Se presten a título oneroso desde el país hacia el exterior, lo que se demostrará con el comprobante de pago que corresponda y siempre que la operación sea anotada en el Registro de Ventas e Ingresos.

b) El exportador sea una persona domiciliada en el país.

c) El usuario o beneficiario del servicio sea una persona no domiciliada en el país.

d) El uso, la explotación o el aprovechamiento de los servicios por parte del no domiciliado tengan lugar en el extranjero.

44 Criterio recogido en las RTF $N^{\circ} 225-5-2000$ y 00423-3-2003.
} 


\subsection{La importación de bienes}

En este supuesto resulta necesario analizar lo dispuesto en la norma sobre la importación de bienes intangibles.

En el inciso g) del artículo 3 de la Ley del IGV se define como importación de bienes intangibles a la adquisición a título oneroso de dichos bienes intangibles que realice un sujeto domiciliado en el país a un sujeto domiciliado en el exterior, siempre que estén destinados a su empleo o consumo en el país.

Lo destacable de esta regulación es que incorpora una definición específica para las operaciones de importación de bienes intangibles, de la cual se colige que, a diferencia de la que regula la venta de dichos bienes, por lo que para esta operación no queda duda alguna que el legislador decidió gravar la totalidad de bienes intangibles al no haberse señalado un listado de bienes como lo hizo en el caso de la venta de bienes muebles.

En ese sentido, podemos afirmar que en toda adquisición de bitcoins que se realice a un sujeto no domiciliado, ya sea por la compra per se o porque se admitan como medio de pago, calificarán como una operación de importación gravada.

Por último, cabe señalar que las operaciones de minería de bitcoins, en tanto califican como una prestación de servicios, en ningún caso se encontrará gravada con el impuesto bajo el supuesto de importación. 


\section{CONCLUSIONES}

Somos conscientes que el trabajo de investigación ha limitado su alcance a, básicamente, tres usos de las criptomonedas (bitcoins), por lo que consideramos que el tema no se agota con lo analizado, no obstante, arribamos a conclusiones que confiamos serán de utilidad para los interesados en las operaciones con criptomonedas (bitcoins):

- Las criptomonedas, entre ellas el bitcoin, no califican como dinero, valores mobiliarios, ni medios de pago.

- Actualmente, bajo el marco normativo vigente, las criptomonedas (bitcoins) en el Perú son bienes intangibles, de carácter informático y digital desarrollados a través de un software. Puede formar parte del activo de una empresa o puede ser empleado como un bien de cambio, dependiendo la actividad a la que se dedica la empresa y la finalidad con la que se adquieran.

- Las operaciones de compra-venta de criptomonedas (bitcoins) y la actividad de minería de bitcoins analizadas en el presente trabajo se encuentran dentro del ámbito de aplicación de la LIR, debido a que las actividades realizadas responden al criterio de la teoría de renta producto.

- La operación de compra-venta de criptomonedas (bitcoins) por una persona natural que no realiza actividad empresarial no se encuentra dentro del ámbito de aplicación de la LIR.

- En el supuesto que las empresas utilicen criptomonedas (bitcoins) como medios de pago se configura una permuta de bienes que se encuentra dentro del ámbito de aplicación de la LIR.

- Debido a la poca información que se requiere para constituirse como usuario de los bitcoins, se genera un problema para el control que ejerce el Estado sobre sus ciudadanos, toda vez que en nuestro ordenamiento jurídico y para el cumplimiento de las funciones de las entidades del Estado, entre ellas la Administración Tributaria, resulta de vital importancia el poder realizar un debido seguimiento a las operaciones que se realizan dentro del país, identificando el origen y el destino del dinero o los bienes que medien en dichas operaciones, a fin de verificar el debido cumplimiento 
de las obligaciones tributarias de los contribuyentes y eventualmente, detectar y combatir la evasión fiscal, tarea que encontraría complejidades con el uso de los bitcoins al no poder identificarse de manera sencilla la identidad de los usuarios sin una regulación normativa que establezca la transparencia en su uso.

- Las operaciones de compra-venta de criptomonedas (bitcoins) en las que se emplean como un medio de pago, al implicar la transferencia de propiedad de las referidas criptomonedas, califican como ventas gravadas con el IGV, de conformidad con lo dispuesto en el inciso a) de la Ley del IGV.

- La actividad de minería de bitcoins califica como una prestación de servicios gravada con el IGV, siempre que el prestador del servicio se encuentre domiciliado en el país y el usuario que lo recibe, lo aproveche en el territorio nacional, de lo contrario estaremos frente a una exportación de servicios inafecta del impuesto.

- La actividad de minería de bitcoins prestadas por un sujeto no domiciliado calificará como una utilización de servicios en el país cuando el usuario aproveche el servicio de validación de operaciones con bitcoins realizadas en el territorio nacional.

- Toda adquisición de bitcoins que se realice a un sujeto no domiciliado ya sea por la compra per se o porque se admitan como medio de pago, calificarán como una operación de importación gravada.

- Si bien las principales operaciones con criptomonedas se encuentran dentro del ámbito de aplicación del Impuesto a la Renta y del Impuesto General a las Ventas, se presentan una diversidad de problemas al momento de aplicar las disposiciones normativas contenidas en las leyes de los citados impuestos, toda vez que se le otorga un tratamiento tributario que no corresponde a la finalidad de la criptomoneda como medio de pago, por lo que resulta necesario una regulación especial que le otorgue un tratamiento tributario similar a los bienes que tienen una finalidad similar. 


\section{RECOMENDACIONES}

A continuación, ensayamos las siguientes recomendaciones:

- Consideramos necesaria una regulación tributaria especial para la aplicación del Impuesto a la Renta y el Impuesto General a las Ventas para las operaciones de compra-venta de bitcoins y en las que se emplee como medio de pago, toda vez que su finalidad no difiere de la de una divisa, correspondiendo otorgarle un tratamiento tributario similar.

- Resulta imperiosamente necesario modificar la Ley del Impuesto a la Renta y la Ley del Impuesto General a las Ventas, a fin de actualizarlas, dado que dichas normas fueron aprobadas por Decretos Legislativos que datan de más de 20 años de antigüedad. La necesidad radica en incorporar disposiciones que permitan tanto al contribuyente como a la Administración Tributaria, contar con la seguridad jurídica necesaria que ameritan las operaciones con las tecnologías que se van desarrollando con el tiempo. 


\section{REFERENCIAS}

Alva, Mario (2012) "El Impuesto a la Renta y las Teorías que determinan su afectación". Recuperado de:

http://blog.pucp.edu.pe/blog/blogdemarioalva/2012/03/01/el-impuesto-a-larenta-y-las-teorias-que-determinan-su-afectacion/

Allemant, Humberto (2004) "Tratamiento para Efectos del Impuesto a la Renta de los Ingresos Provenientes de Operaciones con Terceros". VIII Jornadas Nacionales de Derecho Tributario. Recuperado de: http://www.ipdt.org/editor/docs/02_VIIIJorIPDT_HAS-OMV.pdf

Antoine Bouveret y Vikram Haksar (2018) ¿Qué son las criptomonedas? Finanzas y Desarrollo. Recuperado de: https://www.imf.org/external/pubs/ft/fandd/spa/2018/06/pdf/basics.pdf

Antolini Guido (2017) Bitcoin y las monedas virtuales en el derecho argentino: ¿qué son y cómo están reguladas? Recuperado de: http://repositorio.udesa.edu.ar/jspui/handle/10908/15619

Asociación de Supervisores Bancarios de las Américas (2017) Medios de Pago. Recuperado de: http://www.asba-supervision.org/PEF/medios-de-pago/medios-de-pago.shtml

Asbanc Semanal N $N^{\circ} 274$ (2018) Una Mirada a las Criptomonedas. Recuperado de: https://www.asbanc.com.pe/Publicaciones/ASBANC\%20Semanal\%20274.pdf

BBVA Research (2015) "Dinero electrónico”. En Situación Economía Digital, JulioAgosto 2015. Recuperado de: https://www.bbvaresearch.com/wpcontent/uploads/2015/08/Situacion_Economia_digital_jul-ago15-Cap5.pdf

Banco Central Europeo (2018) ¿Qué es el bitcoin? Recuperado de: https://www.ecb.europa.eu/explainers/tell-me/html/what-is-bitcoin.es.html

Banco Central de Reserva del Perú (2019) Ley N² 29440: Ley de los Sistemas de Pagos y de Liquidación de Valores. Recuperado de: http://www.bcrp.gob.pe/transparencia/datos-generales/marco-legal/ley-de-lossistemas-de-pagos-y-de-liquidacion-de-valores.html

Banco Central de Reserva del Perú (s.f.) Glosario de Términos Económicos.

Recuperado en:

http://www.bcrp.gob.pe/publicaciones/glosario.html 
Banco Central de Reserva del Perú (s.f.) Glosario de Términos y Preguntas Frecuentes. Recuperado de:

https://www.bcrp.gob.pe/sistema-financiero/glosario.html

Banco Central de Reserva del Perú (s.f.) Riesgos de las Criptomonedas. Recuperado de: http://www.bcrp.gob.pe/sistema-financiero/articulos/riesgos-de-lascriptomonedas.html

Banco Mundial (2018) ¿Pueden las criptomonedas y la tecnología de cadena de bloques ayudar a combatir la corrupción? Recuperado de:

https://blogs.worldbank.org/es/voices/pueden-las-criptomonedas-y-latecnologia-de-cadena-de-bloques-ayudar-a-combatir-la-corrupcion

Blundell-Wignall, A. (2014) "The Bitcoin Question: Currency versus Trust-less Transfer Technology", OECD Working Papers on Finance, Insurance and Private Pensions, No. 37, OECD Publishing, Paris. Recuperado de: https://doi.org/10.1787/5jz2pwjd9t20-en.

Bravo, Jorge (2002), "La renta como materia imponible en el caso de actividades empresariales y su relación con la contabilidad". VII Jornadas Nacional de Tributación. Recuperado de: http://www.ifaperu.org/uploads/articles/8_03_CT28_JABC.pdf

Buybitcoinworlwide.com (2018) Historial del precio del Bitcoin. Recuperado de: https://www.buybitcoinworldwide.com/es/precio/

Candia, Salvador (2018) "Bitcoin: ¿En cuántos lugares del Perú puede pagar con ellos?. En El Comercio. Recuperado de: https://elcomercio.pe/economia/peru/lugares-peru-pagar-bitcoins-noticia-488585

Centro Interamericano Jurídico - Financiero (CIJF). Oficio $\mathrm{N}^{\circ} 000314$. Recuperado de: https://cijuf.org.co/normatividad/oficio/2018/oficio-000314.html-0

Chiu, Jonathan y Koeppl, Thorsten (2017) The Economics of Cryptocurrencies. Recuperado de: https://www.chapman.edu/research/institutes-and-centers/economic-scienceinstitute/_files/ifree-papers-and-photos/koeppel-april2017.pdf

Cipriano, Manuel (2015) “Aspectos Jurídicos del Dinero Electrónico: Instrumento de Inclusión Financiera. El Modelo Perú. En Revista Derecho \& Sociedad, N 45. Recuperado de: http://revistas.pucp.edu.pe/index.php/derechoysociedad/article/viewFile/15243/1 5711

Christine Lagarde (2018). Vientos de Cambio: Razones para una nueva moneda digital. Recuperado de:

https://www.imf.org/es/News/Articles/2018/11/13/sp111418-winds-of-changethe-case-for-new-digital-currency 
Coinmap.org (2018) Worldview venues. Recuperado de: https://coinmap.org/\#/world/-7.25622064/-77.90130615/2

Congreso de la República del Perú (2018). Carpeta Temática: Evasión y Elusión Tributaria. Recuperado de:

http://www.congreso.gob.pe/carpetatematica/2018/carpeta_074/normas_extranje $\underline{\text { ras/ }}$

Constance, Hunter (2018) Crypto economics. En Institutionalization of cryptoassets: KPMG (p.1-42). Recuperado de:

https://assets.kpmg/content/dam/kpmg/us/pdf/2018/11/institutionalizationcryptoassets.pdf

Consultas $N^{\circ}$ V1028-15 y V1029-15 (30 de marzo de 2015). Recuperado de: https://petete.tributos.hacienda.gob.es/consultas

Consulta $\mathrm{N}^{\circ}$ V0999-18 (18 de abril de 2018). Recuperado de: https://petete.tributos.hacienda.gob.es/consultas

Consulta $N^{\circ}$ V1069-19 (20 de mayo de 2019). Recuperado de: https://petete.tributos.hacienda.gob.es/consultas

Córdova, Alex (2004) El régimen del Impuesto General a las Ventas a los intangibles en el Perú y su implicancia en transacciones internacionales. En Revista: IUS ET VERITAS. Número 29 - Lima: PUCP. Recuperado de: http://revistas.pucp.edu.pe/index.php/iusetveritas/article/viewFile/11731/12295

Diario Gestión 2018. Recuperado de: https://gestion.pe/economia/hay-12-600-peruanos-han-adquirido-criptomonedas229431-noticia/

Diario Gestión 2019. Recuperado de: https://gestion.pe/economia/peru-tercer-pais-mayores-transaccionescriptomonedas-latinoamerica-268891-noticia/

Decreto Supremo Nº90-2013-EF, Reglamento de la Ley Nº 29985, Ley que regula las características básicas del dinero electrónico como instrumento de inclusión financiera. (14 de mayo de 2013). Recuperado de: http://spijlibre.minjus.gob.pe/normativa libre/main.asp

Decreto Supremo N. ${ }^{\circ}$ 093-2002-EF, Texto Único Ordenado de la Ley del Mercado de Valores, (15 de junio del 2002). Recuperado de: http://spijlibre.minjus.gob.pe/normativa libre/main.asp

Decreto Legislativo $N^{\circ}$ 822, Ley sobre el Derecho de Autor. (24 de abril de 1996). Recuperado de: http://spijlibre.minjus.gob.pe/normativa libre/main.asp 
Decreto Legislativo No 823, Ley de Propiedad Industrial. (24 de abril de 1996).

Recuperado de:

http://spijlibre.minjus.gob.pe/normativa libre/main.asp

Decreto Supremo No 179-2004-EF, Texto Único Ordenado de la Ley del Impuesto a la Renta. (8 de diciembre de 2004). Recuperado de:

http://spijlibre.minjus.gob.pe/normativa libre/main.asp

Decreto Supremo No 055-99-EF, Texto Único Ordenado de la Ley del Impuesto

General a las Ventas e Impuesto Selectivo al Consumo. (15 de abril de 1999).

Recuperado de:

http://spijlibre.minjus.gob.pe/normativa_libre/main.asp

Decreto Ley $N^{\circ} 825$, Sobre Impuesto a las Ventas y Servicios. (3 de diciembre de 1976). Recuperado de:

http://spijlibre.minjus.gob.pe/normativa_libre/main.asp

European Central Bank (2012). Virtual Currency Schemes. Recuperado de: https://www.ecb.europa.eu/pub/pdf/other/virtualcurrencyschemes201210en.pdf

Fernández, Julio (2004), "El concepto de Renta en el Perú”. VIII Jornadas Nacionales de Derecho Tributario. Recuperado de: http://www.ipdt.org/editor/docs/07 VIIIJorIPDT JFC.pdf

Fernández, Pablo (2013) "12 cosas que deberías saber antes de usar bitcoins (la ley y el bitcoin)". En Abanlex. Recuperado de:

https://www.abanlex.com/2013/11/12-cosas-que-deberias-saber-antes-de-usarbitcoins/

García, Roque (1978), "Manual del Impuesto a la Renta". Centro Interamericano de Estudios Tributarios (CIET) Organización de Estados Americanos, Buenos Aires. Recuperado de:

https://documents.tips/documents/4-manual-impuesto-a-la-renta-garciamullin.html

Glosario de Términos Económicos del Banco Central de Reserva del Perú. Recuperado en:

http://www.bcrp.gob.pe/publicaciones/glosario.html

Gregersen, Erick (2016) bitcoin Encyclopædia Britannica Inc. Recuperado de: http://academic.eb.com.ezproxy.ulima.edu.pe/levels/collegiate/article/Bitcoin/57 $\underline{4115}$

Islas, Paulina (2017) Bitcoin: su naturaleza jurídica. Recuperado de: https://idconline.mx/corporativo/2017/12/22/bitcoin-su-naturaleza-juridica

Kauflin, Jeff (2018) Forbes. Recuperado de: https://www.forbes.com/sites/jeffkauflin/2018/02/07/cryptocurrency-richestpeople-crypto-bitcoin-ether-xrp/\#1b16934172d3 
Krugman, Paul y Robin Wells (2014) "Dinero, banca y sistema de reserva federal". Macro Economía. España: Editorial Reverté S.A.

Ley N. ${ }^{\circ} 29985$, Ley de Dinero Electrónico. (17 de enero del 2013). Recuperado de: http://spijlibre.minjus.gob.pe/normativa_libre/main.asp

Ley $\mathrm{N}^{\circ} 30404$, Ley que prorroga la vigencia de beneficios y exoneraciones tributarias. (30 de diciembre de 2015). Recuperado de:

http://spijlibre.minjus.gob.pe/normativa libre/main.asp

Ley 21/2011, Dinero Electrónico. Recuperado en Boletín Oficial del Estado Nº179 (27 de junio). Recuperado de:

http://spijlibre.minjus.gob.pe/normativa libre/main.asp

Ley $N^{\circ} 27287$, Ley de Títulos Valores. (publicada el 19 de junio de 2000). Recuperado de:

http://spijlibre.minjus.gob.pe/normativa_libre/main.asp

Ley N ${ }^{\circ}$ 29440, Ley de los Sistemas de Pagos y de Liquidación de Valores. (19 de noviembre de 2009). Recuperado de:

http://spijlibre.minjus.gob.pe/normativa libre/main.asp

Ley $\mathrm{N}^{\circ} 28194$, Ley para la Lucha contra la Evasión y para la Formalización de la Economía. (26 de marzo de 2004). Recuperado de:

http://spijlibre.minjus.gob.pe/normativa libre/main.asp

Ley 35/2006, del Impuesto sobre la Renta de las Personas Físicas y de modificación parcial de las leyes de los Impuestos sobre Sociedades, sobre la Renta de no Residentes y sobre el Patrimonio. Boletín Oficial Número 285 (29 de noviembre de 2006). Recuperado de:

https://www.boe.es/buscar/pdf/2006/BOE-A-2006-20764-consolidado.pdf

Ley $\mathrm{N}^{\circ}$ 27430, Reforma Tributaria. (29 de diciembre de 2017). Boletín Oficial Número 337 (p. 3): Recuperado de:

http://www.casi.com.ar/sites/default/files/LEY\%2027430\%20reforma\%20tributa ria.pdf

Library of Congress (s.f.) Regulation of Cryptocurrency in Selected Jurisdictions.

Recuperado de:

https://www.loc.gov/law/help/cryptocurrency/index.php

Luque, Javier (1999) El Aspecto Espacial en la Hipótesis de Afectación del Impuesto General a las Ventas. Recuperado de: http://www.ifaperu.org/uploads/articles/29 05 CT26 JLB.pdf

Normas Internacionales de Contabilidad 38 - Activos Intangibles. Recuperado de: https://www.mef.gob.pe/contenidos/conta publ/con nor co/vigentes/nic/NIC 0 38_2014.pdf 
Medrano, Humberto (2011) Impuesto a la Renta y Determinación del Costo Computable. IUS ET VERITAS, 21(42), 320-327. Recuperado de: http://revistas.pucp.edu.pe/index.php/iusetveritas/article/view/12096

Meza, Anthony y Vega, Milton (2017). Monedas Virtuales: qué son y qué retos presentan a las autoridades. Recuperado de:

http://www.bcrp.gob.pe/docs/Publicaciones/Revista-Moneda/moneda172/moneda-172-04.pdf

Ministerio de la Presidencia, Relaciones con las Cortes y Memoria Democrática. Gobierno de España (2018). Resolución de 8 de enero de 2018, de la Dirección General de la Agencia Estatal de Administración Tributaria, por la que se aprueban las directrices generales del Plan Anual de Control Tributario y Aduanero de 2018. Boletín Oficial del Estado $\mathrm{N}^{\circ} 20$. Recuperado de: https://www.boe.es/buscar/doc.php?id=BOE-A-2018-792

Montoya, Karina (2016) "Dinero electrónico: nueve entidades financieras usarán billetera móvil Bim”. En Semana Económica.com. Recuperado de: http://semanaeconomica.com/article/mercados-y-finanzas/banca-yfinanzas/180011-dinero-electronico-entidades-financieras-billetera-movil-bim/

Nakamoto, Satoshi (2008) "Bitcoin: Un sistema de dinero en efectivo electrónico peerto-peer". Recuperado de: https://bitcoin.org/bitcoin.pdf

OECD (2018) "Tax Challenges Arising from Digitalisation - Interim Report 2018: Inclusive Framework on BEPS", OECD/G20 Base Erosion and Profit Shifting Project, OECD Publishing, Paris. Recuperado de: https://doi.org/10.1787/9789264293083-en.

OroyFinanzas.com (2015) "Hacienda declara el Bitcoin exento de IVA en España". En OroyFinanzas.com Diario digital del dinero. Recuperado de: https://www.oroyfinanzas.com/2015/04/bitcoin-esta-exento-iva-espana/

Oficio $\mathrm{N}^{\circ} 20436$ (2 de agosto de 2017) Recuperado de: https://www2.deloitte.com/content/dam/Deloitte/co/Documents/tax/Documentos BoletinAsesor/impuestoscorporativos/septiembre2017/cuartasemana/Concepto\% 20DIAN20436 17.pdf

Oficio $\mathrm{N}^{\circ} 000314$ (7 de marzo de 2018). Recuperado de: https://cijuf.org.co/normatividad/oficio/2018/oficio-000314.html

Ordinario $\mathrm{N}^{\circ} 963$ (14 de mayo de 2018). Recuperado de: http://boletinderecho.udp.cl/docs/anuariodt/2018/at2018ja.pdf

Plan Anual de Control Tributario y Aduanero de 2018. Boletín Oficial Número 20. Recuperado de: https://www.boe.es/boe/dias/2018/01/23/pdfs/BOE-A-2018-792.pdf 
Real Academia Española (s.f.). Recuperado de:

https://dle.rae.es/intangible? $\mathrm{m}=$ form

Regulación de Bitcoin en jurisdicciones seleccionadas. Library of Congress.

Recuperado de:

https://www.loc.gov/law/help/bitcoin-survey/index.php

Small, Stephen. Bitcoin: The Napster of currency. Vol.37, de Houston Journal of

International Law, 581-641. Houston: University of Houston Law Center, 2015.

Recuperado de:

http://www.hjil.org/articles/hjil-37-2-small.pdf

Tribunal de Justicia (2015) Sentencia de la Quinta Sala de 22 de octubre de 2015.

Recuperado de:

http://curia.europa.eu/juris/document/document.jsf?docid=170305\&doclang=ES

Vega, Milton (2013) "Dinero electrónico: innovación en pagos al por menor para promover la inclusión”. En Revista Moneda 153: Política monetaria ante la incertidumbre. Recuperado de:

http://www.bcrp.gob.pe/docs/Publicaciones/Revista-Moneda/moneda153/moneda-153-04.pdf

Villanueva, Walker (2009) Estudio del Impuesto al Valor Agregado en el Perú. Análisis, Doctrina y Jurisprudencia. Lima: Universidad ESAN: Tax Editor

Zegarra, Juan Carlos (2005) “Aplicación del Principio de Especialidad en las Normas Tributarias". Recuperado de:

http://www.ipdt.org/editor/docs/05_Rev43_JCZV.pdf 


\section{ANEXO 1: GLOSARIO Y DEFINICIONES RELACIONADAS AL BITCOIN}

Para conocer a detalle qué es el Bitcoin y cómo opera, resulta necesario primero desarrollar algunos de los términos que usualmente se emplean cuando se mencionan a los bitcoins, para lo cual emplearemos el glosario contenido en el website oficial del creador del Bitcoin ${ }^{45}$ :

\section{Bitcoin y bitcoin}

Cuando se emplea el término con la primera letra en mayúscula nos referimos al sistema en general o a su concepto, mientras que cuando se emplea con la primera letra en minúscula nos referimos a una unidad de la misma.

\section{Bloque (Block)}

Un bloque es un registro en un sistema indexado de bloques o también conocido como cadena de bloques que contiene las confirmaciones de las transacciones pendientes. Aproximadamente cada 10 minutos, en promedio, un nuevo bloque que incluye nuevas transacciones se anexa a la cadena de bloques a través de la minería de bitcoins.

\section{Cadena de bloques (Blockchain)}

La cadena de bloques es el registro público de todas las transacciones con bitcoins llevadas a cabo en orden cronológico. Este registro es compartido con todos los usuarios de bitcoins y su finalidad es el de servir como herramienta para verificar la

45 Glosario recuperado de:

https://bitcoin.org/es/vocabulario 
estabilidad de las transacciones y evitar que los mismos bitcoins se empleen en más de una transacción desde la misma cuenta.

\section{Criptografía (Cryptography)}

Es la rama de las matemáticas que permite crear pruebas que proporcionan sofisticados niveles de seguridad. En el caso de Bitcoin, la criptografía brinda niveles de seguridad que prácticamente garantizan que los bitcoins de un usuario no puedan ser utilizados por otros o que se pueda corromper la cadena de bloques. La criptografía también se emplea para encriptar un monedero, de manera que no se pueda utilizar sin una contraseña.

\section{Dirección (Adress)}

La dirección Bitcoin encuentra similitudes con las direcciones físicas o de correo electrónico. Esta dirección es la única información que deberá brindar quien emplee bitcoins para realizar una transacción de pago. Sin embargo, hay una diferencia importante con las direcciones físicas o de correo electrónico, dado que cada dirección Bitcoin sólo debería usarse para una transacción.

\section{Firma criptográfica}

Una firma criptográfica es el mecanismo matemático empeado para demostrar la propiedad sobre un bien. En el caso de Bitcoin, el monedero Bitcoin y la clave privada se vinculan mediante la criptografía Cuando su programa de Bitcoin firma una transacción con la clave privada correspondiente, toda la red puede ver que la firma coincide con los bitcoins gastados, con la ventaja de que dicha firma permanecerá siendo privada.

\section{Minería de bitcoins (Mining)}

La minería de bitcoins es el proceso que a través de cálculos matemáticos realizados por equipos informáticos especializados validan operaciones con criptomonedas realizadas por otros usuarios de la citada criptomoneda, otorgando seguridad al sistema. Los mineros de bitcoins, obtienen por los servicios brindados una comisión de las operaciones que 
validan además de una recompensa en nuevos bitcoins que son liberados por el sistema a favor del minero que encuentra primero la solución. La minería es un mercado especializado y competitivo en el que los beneficios se reparten de acuerdo a la cantidad de cálculos que se hacen.

\section{Monedero (Wallet)}

El monedero Bitcoin funciona tal cual lo hace un monedero físico con la diferencia de que su función es exclusiva para la red Bitcoin. El monedero tiene como mecanismo de seguridad una clave privada que permite gastar los bitcoins asignados insertándose las transacciones efectuadas en la cadena de bloques.

\section{P2P - Punto a Punto (Peer to Peer)}

El término de punto a punto se refiere al sistema que trabaja como una organización colectiva, permitiendo que cada individuo que la integra interactúe directamente con otros. En el caso del Bitcoin, la red se construye de tal manera que cada usuario está transmitiendo transacciones de otros usuarios, sin mediar la intervención de terceros ajenos al sistema. 


\section{ANEXO 2: MAPA MUNDIAL DE ESTABLECIMIENTOS QUE ACEPTAN BITCOINS}

El siguiente gráfico muestra un mapa mundial en el que se observan las ciudades donde operan establecimientos que aceptan criptomonedas como forma de pago ${ }^{46}$.

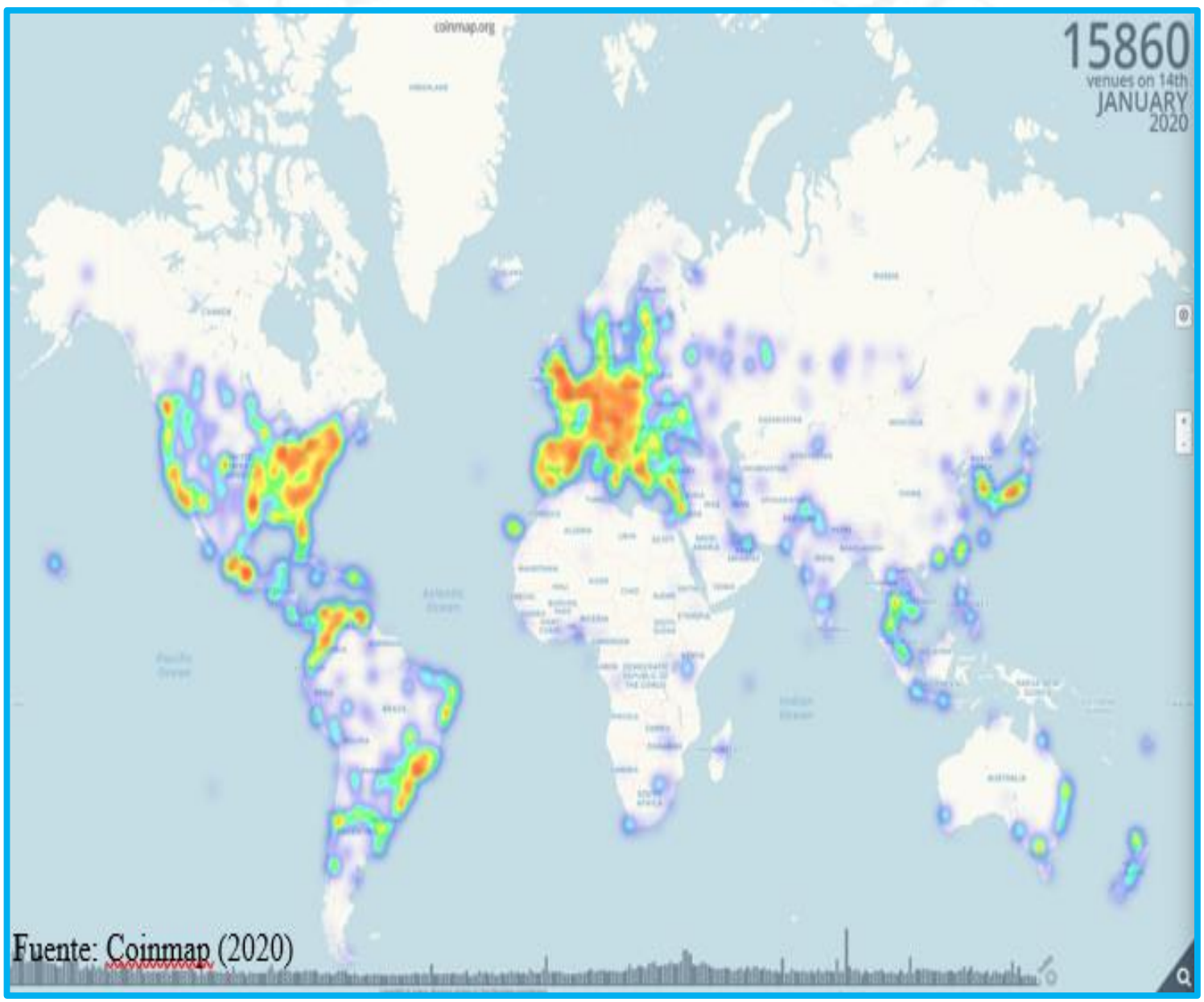

46 A enero de 2020, existen aproximadamente 15,860 establecimientos. En Estados Unidos de Norteamérica, Japón y los países de Europa se concentran la gran mayoría de establecimientos que aceptan criptomonedas como medio de pago. 


\section{ANEXO 3: MAPA DEL PERÚ DE ESTABLECIMIENTOS QUE ACEPTAN BITCOINS}

El siguiente gráfico muestra un mapa del Perú en el que se observa las ciudades dentro del territorio nacional en donde operan establecimientos que aceptan los bitcoins como forma de pago $^{47}$.

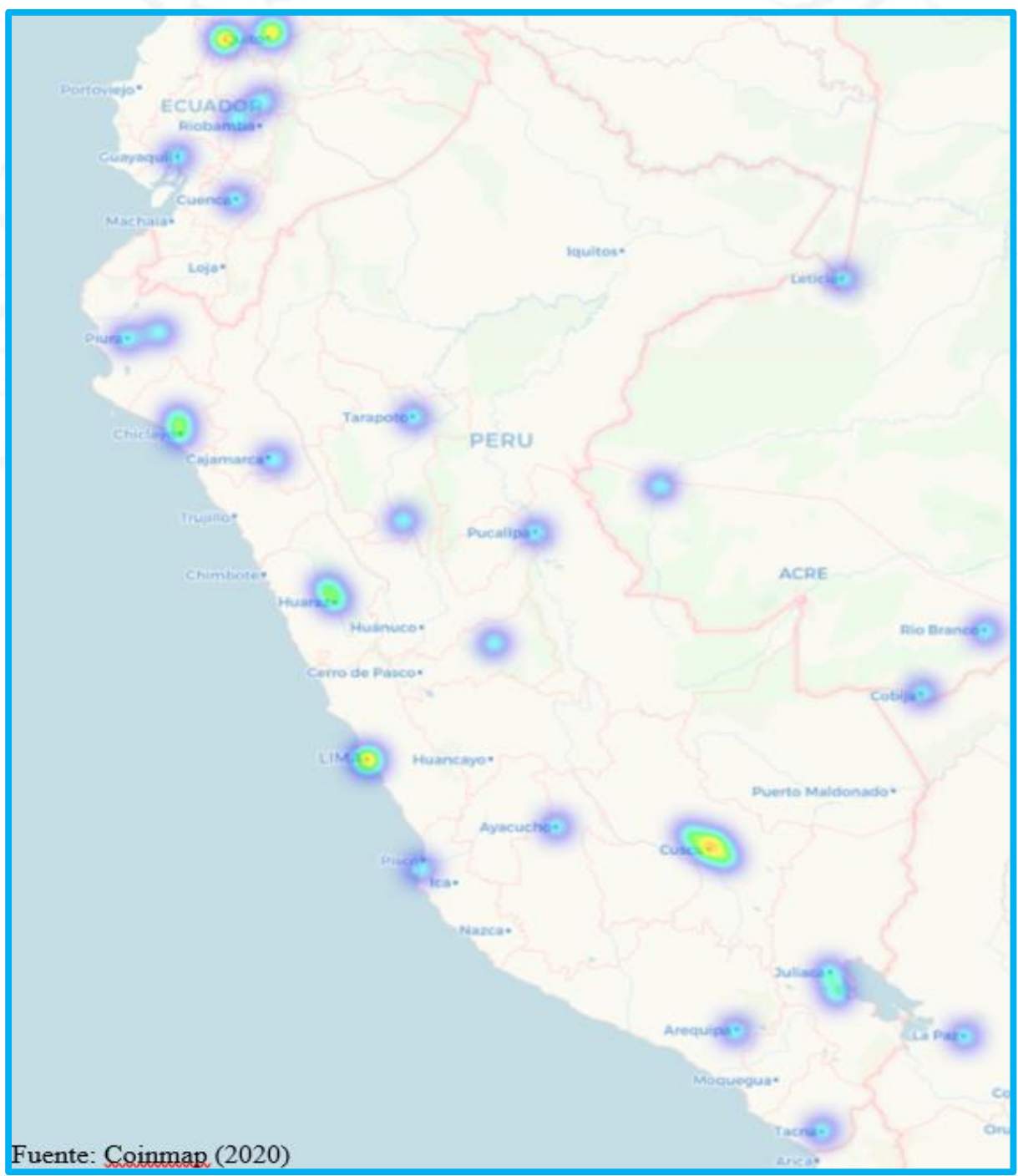

47 A enero de 2020, existen aproximadamente 48 establecimientos. Dichos establecimientos se encuentran principalmente en la ciudad de Lima, Cuzco y Arequipa. 


\section{ANEXO 4: COTIZACIÓN HISTÓRICA DEL BITCOIN}

El siguiente gráfico muestra la cotización histórica del Bitcoin, desde su creación en el 2009 hasta el mes de enero de 2020. El precio al día 6 de enero de 2020 es de \$7,907.27 dólares americanos ${ }^{48}$.

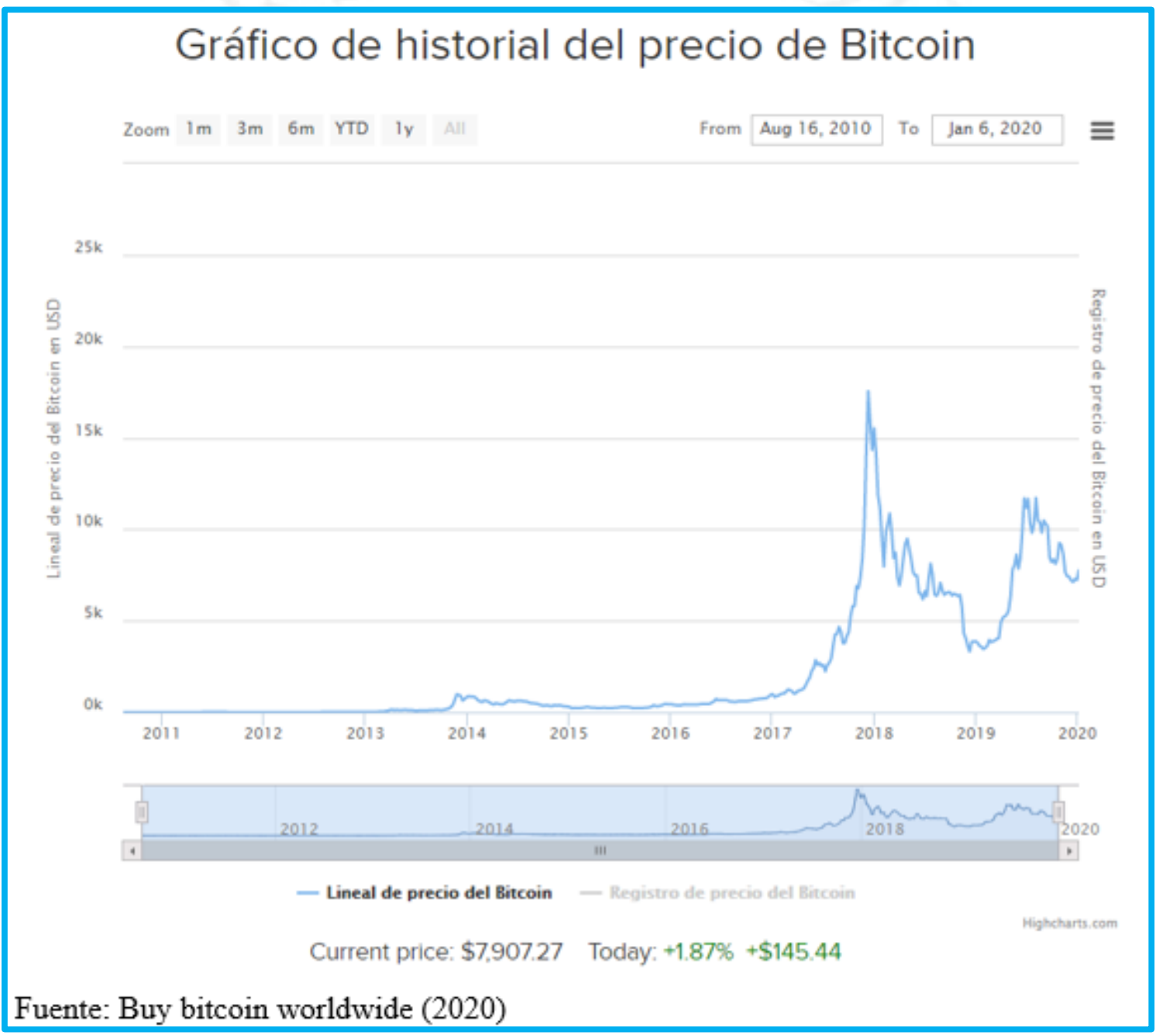

48 Al tipo de cambio vigente a la fecha señalada, el precio del bitcoin es de S/ 26,180.97. 